\title{
Neuroadaptive Changes in
}

\section{5-HT ${ }_{1 \mathrm{~A}}$ Autoreceptor Sensitivity}

\section{Following High-Dose MDMA Treatment.}

\author{
Simon David Fisher
}

A thesis submitted to Victoria University of Wellington

in fulfilment of the requirements for the degree of

Master of Science in

Cognitive and Behavioural Neuroscience

Victoria University of Wellington 


\begin{abstract}
Rationale: There is evidence that the serotonin (5-HT) deficits and related cognitive and mood impairments caused by $+/-3,4-$ methylenedioxymethamphetamine (MDMA) may be mediated by neuroadaptations of the $5-\mathrm{HT}_{1 \mathrm{~A}}$ autoreceptor.

Objectives: The increase in sensitivity of the 5- $\mathrm{HT}_{1 \mathrm{~A}}$ autoreceptor caused by highdose, repeated MDMA treatment was assessed neurochemically, by measuring 5HTP accumulation, and physiologically, via changes in body temperature.

Methods: Experiment 1 confirmed the effects of 8-hydroxy-2-(di-npropylamino)tetralin (8-OH-DPAT) $(0,0.025,0.05,0.1 \mathrm{mg} / \mathrm{kg}$ s.c.) on $5-$ hydroxytryptophan (5-HTP) accumulation following 3-hydroxybenzylhydrazine dihydrochloride (NSD-1015) administration as a valid measure of 5-HT synthesis and hence 5- $\mathrm{HT}_{1 \mathrm{~A}}$ autoreceptor sensitivity in rats. Experiment 2 performed these procedures in additional animals, with half receiving MDMA (4x $10 \mathrm{mg} / \mathrm{kg}$ i.p. at 2 hour intervals) two weeks before testing. Body temperature changes due to the 8-OH-DPAT hypothermic response were tested using a rectal probe. Experiment $2 \mathrm{~b}$ repeated the procedures in additional groups with lower doses of 8-OH-DPAT (0.0125 and $0.00625 \mathrm{mg} / \mathrm{kg}$ s.c.).

Results: No significant changes in 5-HTP accumulation levels or changes in the hypothermic response to 8-OH-DPAT were found between MDMA pretreated rats and controls in Experiments 2 and 2b. Moreover, there was no substantial evidence of expected 5-HT deficits due to high-dose MDMA treatment.

Conclusion: The results do not indicate an increase in sensitivity of the 5-HT1A autoreceptor, and hence the original hypothesis is not supported. However, there were a number of methodological issues, as indicated by the lack of MDMAinduced 5-HT deficits, which prevent a firm conclusion from being drawn. Future research is outlined to overcome these issues.
\end{abstract}




\section{Acknowledgements}

To all those who supported...

My supervisor, Prof Susan Schenk - thanks for the introduction to this research and the guidance along the way.

My lab mentor extraordinaire, Joyce Colussi-Mas - thanks for all the instruction, assistance and general awesomeness throughout the year.

The lab crew, and especially Richard, for all the help.

And to my friends, family and partner, Celine - thanks for being there and caring. 


\section{Table of Contents}

List of Abbreviations................................................................................... 1

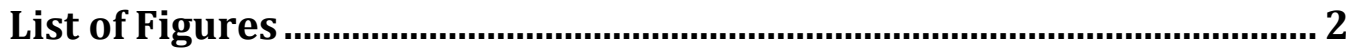

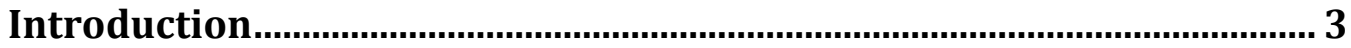

MDMA Epidemiology and Patterns of Use ……………………………………………. 4

Adverse Acute and Long-Term Effects of MDMA...................................................... 5

MDMA Pharmacology

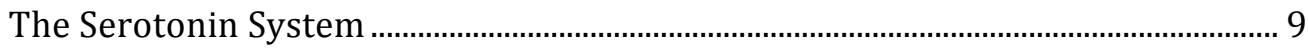

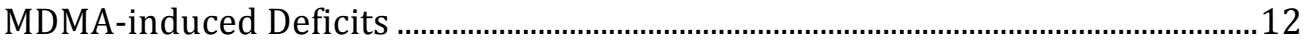

Neuroadaptations in the $5-\mathrm{HT}_{1 \mathrm{~A}}$ receptor …………….............................................17

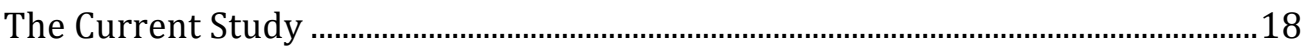

Method......................................................................................................... 20

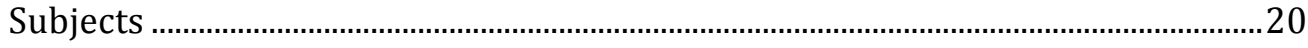

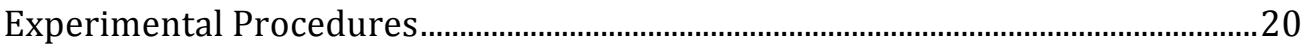

Experiment 1 - Method validation ...........................................................................22

Experiment 2 - Effect of MDMA pretreatment on 5-HT 1 A sensitivity .......................23

Experiment 2b - Additional 8-OH-DPAT doses............................................................23

Statistical Analyses....................................................................................................... 24

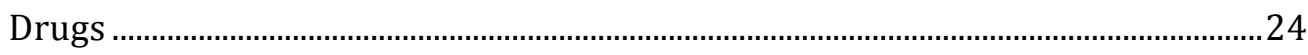

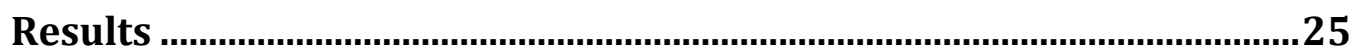

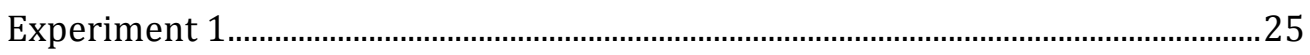

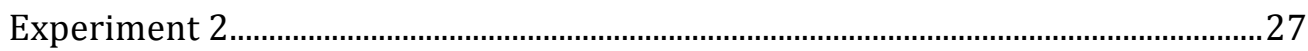

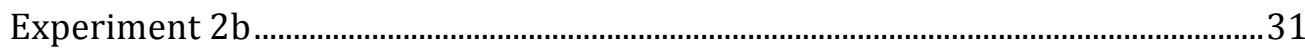

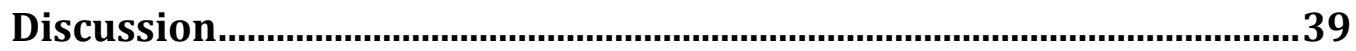

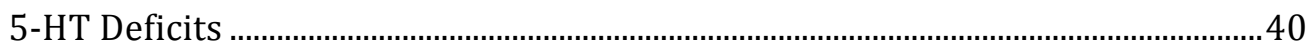

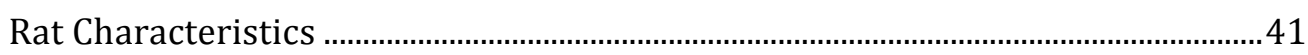

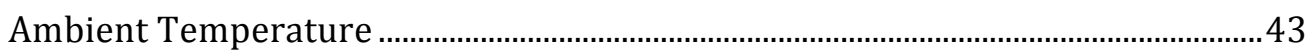

Hypothermic Response ................................................................................................. 43

Methodological Issues and Stress ........................................................................... 44

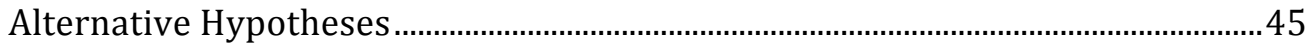

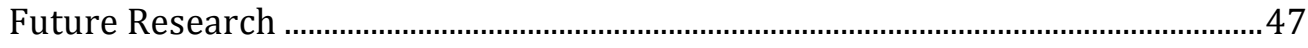

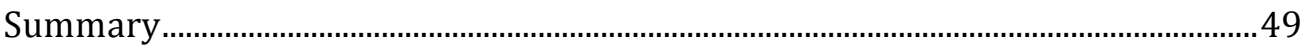

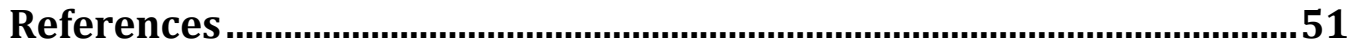




\title{
List of Abbreviations
}

\author{
MDMA 3,4-Methylenedioxymethamphetamine \\ MDA 3,4-methylene-dioxyamphetamine \\ 5-HT Serotonin \\ $5-\mathrm{HT}_{1 \mathrm{~A}} \quad$ Serotonin 1A receptor subtype \\ 5-HTP 5-hydroxy-L-tryptophan \\ 5-HIAA 5-Hydroxyindoleacetic acid \\ TPH Tryptophan hydroxylase \\ SERT 5-HT Transporter \\ FC Frontal Cortex \\ St Striatum \\ Hip Hippocampus \\ DRN Dorsal raphe nuclei \\ MRN Median raphe nuclei \\ 8-OH-DPAT 8-Hydroxy-2-(di-n-propylamino)tetralin \\ NSD-1015 3-hydroxybenzylhydrazine dihydrochloride \\ GFAP Glial fibrillary acidic protein
}




\section{List of Figures}

Fig. 1. The effects of NSD-1015 (100 mg/kg i.p.) in the frontal cortex on 5-HTP accumulation (a), 5-HT tissue levels (b) and 5-HIAA tissue levels (c) 30 minutes following NSD-1015 administration

Fig. 2. 5-HTP accumulation (ng/mg) one hour following 8-OH-DPAT treatment $(0,0.025,0.05$ or $0.1 \mathrm{mg} / \mathrm{kg}$ s.c. $)$ and 30 minutes following NSD-1015 $(100 \mathrm{mg} / \mathrm{kg}$ i.p.) treatment.

Fig. 3. 5-HTP accumulation in the frontal cortex (a), striatum (b) and hippocampus (c) in rats two weeks following pretreatment with MDMA (4x 10 $\mathrm{mg} / \mathrm{kg}$ i.p.) or saline 29

Fig. 4. 5-HT and 5-HIAA tissue levels in the frontal cortex (a, d), striatum $(\mathrm{b}, \mathrm{e})$ and the hippocampus (c, f) in rats two weeks following MDMA (4x 10 $\mathrm{mg} / \mathrm{kg}$ i.p.) or saline pretreatment, and without 8-OH-DPAT but with NSD-1015 $(100 \mathrm{mg} / \mathrm{kg}$ i.p.) administration 30 minutes prior to brain extraction.

Fig. 5. Change in rectal core body temperature as a result of 8-OH-DPAT treatment for both MDMA (4x $10 \mathrm{mg} / \mathrm{kg}$ i.p.) and saline pretreated rats

Fig. 6. 5-HTP accumulation in the frontal cortex (a), striatum (b) and hippocampus (c) in rats two weeks following pretreatment with MDMA (4x 10 $\mathrm{mg} / \mathrm{kg}$ i.p.) or saline

Fig. 7. 5-HT tissue levels for the frontal cortex (a), striatum (b) and hippocampus (c) of rats that received either Saline or MDMA (4x 10mg/kg i.p.) pretreatment, without 8-OH-DPAT or NSD-1015 administration. 5-HIAA levels for the frontal cortex (d), striatum (e), hippocampus (f) for the same groups . 34

Fig. 8. Change in rectal core body temperature as a result of 8-OH-DPAT treatment for both MDMA (4x $10 \mathrm{mg} / \mathrm{kg}$ i.p.) and saline pretreated rats 35

Fig. 9. Relationship between 5-HT tissue levels and pretreatment weight, in the frontal cortex (a), striatum (b) and hippocampus (c) for rats in the MDMA pretreatment (4x $10 \mathrm{mg} / \mathrm{kg}$ i.p.), no 8-OH-DPAT, no NSD-1015 control group 


\section{Introduction}

Substance abuse and dependence are serious global problems with many social and economic impacts. A positive step in recent years has been the return of health to the core of drug policy. Substance dependence is now seen as a treatable condition, with new evidence-based methods of helping those affected (United Nations Office on Drugs and Crime (UNODC), 2010). One grouping of abused substances are amphetamine-type stimulants, which includes amphetamine, methamphetamine, and 3,4-Methylenedioxymethamphetamine (MDMA) along with its analogues. MDMA, or 'ecstasy' as it is known on the street, rose out of a popularity surge in the United States and parts of Europe in the 1980s to become the global phenomenon it is today (UNODC).

The ring-substituted amphetamine derivative was first synthesised by the German pharmaceutical company Merck in 1912 as an intermediate compound in the synthesis of other drugs (Benzenhöfer \& Passie, 2006; Freudenmann, Oxler, $\&$ Bernschneider-Reif, 2006). However, MDMA remained largely on the shelf until 1976 when it was re-synthesised by the experimental psychopharmacologist Alexander Shulgin (Shulgin \& Nichols, 1978; McDowell \& Kleber, 1994). After it was first informally distributed by Shulgin and others for experimentation and as a possible tool in psychotherapy, MDMA soon crossed over into wider public use, where it was associated with early 1980s dance and rave scenes in the US (Gowing, Henry-Hedwards, Irvine, \& Ali, 2001). The increasing popularity of MDMA, together with growing evidence of its neurotoxicity in laboratory animals, led to its being scheduled in the US, UK and other countries as a Class 1 illicit drug in the early 1980s (McDowell \& Kleber, 1994; Nutt, 2008).

MDMA has distinct pharmacological effects from other stimulants in that it produces a unique sense of warmth and empathy for others (Greer \& Tolbert, 1998). Because of this unique combination of stimulant and pro-social effect, some researchers argue that it represents a new class of drugs, and declare MDMA as the archetypical 'entactogen' (Nichols \& Oberlender, 1990). These aspects of MDMA have also led some researchers and therapists to believe MDMA may be a useful tool in psychotherapy. Indeed, before MDMA was classified as a controlled substance, a number of psychiatrists used MDMA as an 
adjunct to psychotherapy, reporting that MDMA could decrease feelings of fear and raise empathy in patients while maintaining a clear-headed, alert state of consciousness (Greer \& Tolbert, 1998). Interest in MDMA's use in this respect has recently been rekindled with a clinical trial for MDMA-assisted psychotherapy in subjects with posttraumatic stress disorder being published (Mithoefer, Wagner, Mithoefer, Jerome, \& Doblin, 2010).

\section{MDMA Epidemiology and Patterns of Use}

Trends in global MDMA consumption, manufacture and trafficking are dynamic, becoming more prevalent in new locations around the world (19 countries recently reported an increase) while remaining stable or declining in others (UNODC, 2010). In the US, following a spike in MDMA use in the early 2000s, 2008 survey results show a maintenance of the lifetime prevalence rate among 19 to 28 year olds (13.1\%) that is comparable to cocaine (14.8\%) and hallucinogens (14.8\%) (Johnston, O’Malley, Bachman, \& Schulenberg, 2010). The British Crime Survey (2010) reveals a similar trend, in which MDMA use in England and Wales has remained fairly stable over recent years, with an approximate annual consumption of 60 million 'ecstasy' tablets (Singleton, Murray, \& Tinsley, 2006). Locations where MDMA use is increasing include many parts of the developing world and Asia (UNODC). Moreover, the Oceania region has one of the highest annual, and rising prevalence rates of MDMA use in the world (UNODC). In New Zealand for example, a survey found that the population prevalence of MDMA consumption increased from 5.2\% in 2004 to $7.5 \%$ in 2006 (Wilkins, Griffiths, \& Sweetsur, 2009).

Research also shows that users increase their MDMA dose with experience, and recent studies show trends of higher doses of MDMA and use of the drug in more diverse situations. For instance, Fox, Parrott and Turner (2001) compared three MDMA user subgroups divided by MDMA experience: low users (1 - 99 tablets in lifetime), medium users (100 - 499 tablets) and high users (500+ tablets). As MDMA experience increased, there was a parallel increase in the number of tablets normally consumed per occasion, together with a greater maximum number of tablets taken on any one occasion. Additionally, in a recent survey of drug use by dance club attendees, Measham and Moore (2009) found a trend 
towards increased dosage of MDMA. Several studies have also found a trend towards MDMA use outside of the electronic music scene, in increasingly diverse populations and situations (Wilkins, Bhatta, Pledger, \& Casswell, 2003; Wilkins, Sweetsur, \& Casswell, 2006).

As likely consequences of increases in prevalence and dosing, MDMA abuse and dependence are serious issues. Cottler, Leung and Abdallah (2009) interviewed 593 MDMA users across three different cities and found that $15 \%$ and 59\% met DSM-IV criteria for MDMA abuse and dependence respectively. In the assessment, 'continued use despite knowledge of physical/psychological problems' (87\%) and 'withdrawal' (68\%) were the two most prevalent dependence criteria. An earlier study by Cottler (2009) found similar results, with $43 \%$ of MDMA users meeting criteria for dependence and $34 \%$ for abuse. Furthermore, in a 2003 survey, $59 \%$ of participants reported tolerance to the effects of MDMA (Verheyden, Henry, \& Curran, 2003) and it is common for users to report a reduction in the positive effects of MDMA within the first few occasions of use (Peroutka, Newman, \& Harris, 1988; Topp, Hando, Dillon, Roche, \& Solowij, 1999; Parrott, 2001; Scholey et al., 2004). As a result of tolerance, which is an important criterion for substance dependence, drug intake is often escalated through methods such as increases in dose to sustain a high, and changing administration routes (Fox et al., 2001; Verheyden et al., 2003; Carlson, Falck, McCaughan, \& Siegal, 2004; Scholey et al., 2004). The research described here illustrates how MDMA use is maintained at high rates or is increasing around the world, and is coupled with a trend of increases in dose and substantial evidence of clinical abuse and dependence.

\section{Adverse Acute and Long-Term Effects of MDMA}

Accumulating evidence indicates that MDMA can cause serious acute and long-term health concerns. Acute adverse effects of MDMA intoxication in humans include cardiac arrhythmias, hypertension, hyperthermia, serotonin syndrome, hyponatremia, liver problems, seizures, coma, and, in rare cases, death (Schifano, 2004). In rats, with which a large proportion of substance abuse research occurs, MDMA produces a range of acute behavioural responses including hyperkinesis, increased heart rate, and symptoms of serotonin syndrome 
such as forepaw treading, flattened body posture, and head weaving (Gold, Koob, \& Geyer, 1988; Spanos \& Yamamoto, 1989; O’Cain, Hletko, Ogden, \& Varner, 2000). MDMA has also been found to produce disruptions in thermoregulation in rats, termed poikilothermia, which leads to hypothermia in cold environments and hyperthermia in mild and hot environments (Nash, Meltzer, \& Gudelsky, 1988; Dafters, 1995; Dafters \& Lynch, 1998).

Long-term MDMA abuse is associated with persistent cognitive impairments and mood disturbances, and increased risk of psychological disorders (Morgan, 2000; Parrott et al., 2002). In MDMA users, an array of neuropsychological tests have revealed that working, short-term and long-term memory, and executive functioning, were all significantly impaired in regular and heavy users (McCann, Mertl, Eligulashvili, \& Ricaurte, 1999; Reneman, Booij, Schmand, van den Brink, \& Gunning, 2000; Fox et al., 2001; McCardle, Luebbers, Carter, Croft, \& Stough, 2004). Additionally, more extensive incidents of emotional disorders, such as depression and anxiety disorders, have been found in heavy MDMA users (Morgan, 2000; Fox et al., 2001; Parrott et al., 2002).

It is important to note that there are a range of issues related to human drug abuse research that limit the validity and reliability of MDMA research in humans. Such issues include an inability to accurately ascertain drug taking history due to significant polydrug use (Scholey et al., 2004), variance in the actual MDMA content of so-called ecstasy tablets (Parrott, 2004), reliance on memory to recall past drug taking events, and self-report reliability issues due to MDMA's illegal status. However, notwithstanding these limitations, the research still paints a clear picture of long-term impairments associated with MDMA abuse in humans.

The long-term effects of MDMA have also been extensively studied in laboratory animals, such as the rat. These studies allow much greater experimental control and scope in not being limited by the constraints associated with human research. The animal literature supports the human research in finding that MDMA exposure is associated with persistent impairments in cognitive functioning in both rats and nonhuman primates, including impaired spatial memory, executive functioning, and attention (McCann et al., 1999; Williams et al., 2003; Sprague, Preston, Leifheit, \& Woodside, 2003; Vorhees, Reed, Skelton, 
$\&$ Williams, 2004; Cohen et al., 2005). For example, Sprague et al. (2003) tested MDMA pretreated (2x $20 \mathrm{mg} / \mathrm{kg}$ s.c., given $12 \mathrm{~h}$ apart) rats in the Morris water maze and found significant memory impairments. Further impairments were found by Marston, Reid, Lawrence, Olverman and Butcher (1999) in a delayed non-match to performance procedure, where MDMA pretreated animals exhibited short-term memory impairments.

There is also evidence that MDMA can have persistent anxiogenic effects in rats as shown through behavioural measures of anxiety, such as social interaction and emergence tests (Morley, Gallate, Hunt, Mallet, \& McGregor, 2001; Gurtman, Morley, Li, Hunt, \& McGregor, 2002; McGregor et al., 2003b; Sumnall, O’Shea, Marsden, \& Cole, 2004). These tests involve recording the animal's behaviour in potentially anxiety-inducing scenarios, for instance emerging from a home cage into an open arena. Significant increases in anxiety-like behaviour in an elevated plus-maze have been reported in rats pretreated with MDMA (4x $5 \mathrm{mg} / \mathrm{kg}$ i.p. for 2 days) (Gurtman et al.) and significantly attenuated social interaction measures in rats have also been reported weeks after MDMA pretreatment $(7.5 \mathrm{mg} / \mathrm{kg}$ i.p., twice daily for 3 days) (Fone et al., 2002). Furthermore, in the forced swim test of depression-like behaviour, MDMA pretreated rats (4x 5mg/kg i.p. for 2 days) exhibited reduced escape attempts and increased immobility (Mcgregor et al., 2003a).

Conversely, some studies have found no significant long-term impairments in learning and memory tasks in rats, despite observing marked physiological brain deficits caused by MDMA (Robinson, Castañeda, \& Whishaw, 1993; Seiden et al., 1993; Byrne, Baker, \& Poling, 2000). The different results of these studies could be due to the type of learning and memory task employed, differing MDMA administration procedures, and the tests used not being sensitive enough to detect the impairments produced by MDMA. Despite these complexities, given the potential of MDMA to cause persistent impairments in cognition and mood, it is important to investigate further the mechanisms underlying these impairments and possibilities for their reversal. 


\section{MDMA Pharmacology}

Both (+) and (-) isomers of MDMA are bioactive (Johnson, Hoffman, \& Nichols, 1986; Schmidt, 1987) and ecstasy tablets ingested by humans contain a racemic mixture of both stereoisomers. Upon systemic administration, $\mathrm{N}$ demethylation of MDMA occurs via first-pass metabolism to yield 3,4methylene-dioxyamphetamine (MDA) (de la Torre et al., 2004). MDMA and MDA act to increase the release of the monoamine neurotransmitters serotonin (5HT), dopamine (DA), norepinephrine (NE), and histamine; together with acetylcholine (Nichols, Lloyd, Hoffman, Nichols, \& Yim, 1982; Johnson et al., 1986; McDowell \& Kleber, 1994). MDMA and MDA bind to cell plasma membrane monoamine transporters and are translocated into the cytoplasm, where they are known to act to increase monoamine levels through two mechanisms: reversal of the normal transporter function to release neurotransmitter molecules through their concentration gradients, and an increase of cytoplasmic neurotransmitter concentrations through disruption of vesicular membrane transporters (Schuldiner, Steiner-Mordoch, Yelin, Wall, \& Rudnick, 1993; Green, Cross, \& Goodwin, 1995; Rothman \& Baumann, 2002). MDMA also inhibits the catabolic enzyme monoamine oxidase (MAO) (Leonardi \& Azmitia, 1994), thereby reducing the metabolism of monoamine neurotransmitters and further contributing to their increased activity at the synapse.

Of the monoamines, MDMA preferentially releases 5-HT (Yamamoto, Nash, \& Gudelsky, 1995; Kankaanpää, Meririnne, Lillsunde, \& Seppälä, 1998), with potency, for example, approximately ten times that of methamphetamine (White, Obradovic, Imel, \& Wheaton, 1996). For instance, it has been found that rapidly following systemic administration of $2.5 \mathrm{mg} / \mathrm{kg}$ MDMA there is an approximate increase of $600 \%$ in extracellular serotonin in the frontal cortex, and a 2,600\% increase with $20 \mathrm{mg} / \mathrm{kg}$ MDMA (Gudelsky \& Nash, 1996). The increases in extracellular 5-HT following MDMA administration are predominantly seen in the striatum (Gough, Ali, Slikker, \& Holson, 1991; Sabol \& Seiden, 1998), the frontal cortex (Gartside, McQuade, \& Sharp, 1997), the nucleus accumbens (Kankaanpää et al., 1998), the substantia nigra (Yamamoto et al., 1995), and the hippocampus (Colado \& Green, 1994; Mechan et al., 2002). These areas are 
terminal fields projected to by the 5-HT neurons of the raphe nuclei in the midbrain (Segal, 1975; Sprouse \& Aghajanian, 1988). The 5-HT cell bodies of the raphe nuclei play a critical role in regulating the serotonin system and mediating the effects of MDMA on the brain. To explain these effects further, the fundamentals of this neurotransmitter system and its receptors need to be introduced.

\section{The Serotonin System}

5-HT is a monoamine neurotransmitter in the CNS of humans and other animals. 5-HT cell bodies are situated in the nine raphe nuclei, located along the rostrocaudal midline of the brain stem (Dahlström \& Fuxe, 1964). Serotonergic neurons derive mainly from two raphe nuclei: the dorsal (DRN) and median (MRN) nuclei (Conrad, Leonard, \& Pfaff, 1974). Neurons in these nuclei project predominately to different serotonin terminal regions. The 5-HT pathways to the frontal cortex (FC) and striatum (St) mainly originate from 5-HT neurons located in the DRN, while the 5-HT pathways to the hippocampus (Hip) emanate from both the DRN and MRN, although primarily the MRN (Miller, Richardson, Fibiger, \& McLennan, 1975; Azmitia \& Segal, 1978; Jacobs, Foote, \& Bloom, 1978; Imai, Steindler, \& Kitai, 1986).

Serotonin is synthesised in a metabolic pathway beginning with the essential amino acid L-tryptophan being converted to 5-hydroxy-L-tryptophan (5-HTP) in the rate-limiting step by the enzyme tryptophan hydroxylase (TPH) (Fernstrom \& Wurtman, 1971). This important enzyme is now known to exist in two different isoforms encoded by two different genes: the original TPH, referred to now as TPH1, and the newly discovered isoform, identified as TPH2 (Walther \& Bader, 2003). The two isoforms also differ in their anatomical distribution, with TPH2 being exclusively expressed in the brain and TPH1 primarily in the periphery (Zill et al., 2007). The majority of TPH2 mRNA is synthesised in the raphe nuclei (Patel, Pontrello, \& Burke, 2004; Zill et al., 2007) and is thought to be transported to cortical and subcortical brain regions through axons (Bonkale \& Austin, 2008). In the next step of the metabolic pathway, 5-HTP is converted to 5-HT by aromatic L-amino acid decarboxylase. 5-HT is metabolised by MAO, producing the main metabolite 5-Hydroxyindoleacetic acid (5-HIAA). 
There are at least 16 structurally and pharmacologically distinct mammalian 5-HT receptor subtypes, each belonging to one of seven families based on their primary signalling mechanisms: 5-HT1 to 5-HT7 (Barnes \& Sharp, 1999; Polter $\& \mathrm{Li}, 2010)$. Of particular importance to MDMA's effects on the brain, and a member of the 5-HT1 family, the 5- $\mathrm{HT}_{1 \mathrm{~A}}$ receptor was the first 5-HT receptor to be fully sequenced and is one of the best characterised due to early anxiolytic and antidepressant findings. Morphologically, the 5- $\mathrm{HT}_{1 \mathrm{~A}}$ receptor consists of a single polypeptide chain with seven putative transmembrane domains (Hoyer et al., 1994). Findings from electrophysiological, ligand binding, in situ hybridization and immunocytochemical studies reveal that the $5-\mathrm{HT}_{1 \mathrm{~A}}$ receptor exists as an inhibitory somatodendritic autoreceptor and as a postsynaptic heteroreceptor (Vergé et al., 1986; Sprouse \& Aghajanian, 1987; Sprouse \& Aghajanian, 1988; Sotelo, Cholley, El Mestikawy, Gozlan, \& Hamon, 1990; Chalmers \& Watson, 1991). The 5-HT $1 \mathrm{~A}$ receptor is located on 5-HT neurons and dendrites in the raphe nuclei (autoreceptors) and on non-5-HT neurons in many other subcortical and cortical areas that serotonin neurons project to (heteroreceptors). High 5- $\mathrm{HT}_{1 \mathrm{~A}}$ receptor binding density is found in the DRN and MRN of the raphe nuclei, in the hippocampus, the amygdala and in limbic cortical areas. Medium binding density is found in the olfactory bulb, the thalamus, hypothalamus, and the neocortex. Low or no levels are detected in the basal ganglia and cerebellum (Hall et al., 1985; Vergé et al., 1986; Albert, Zhou, Van Tol, Bunzow, \& Civelli, 1990; Pompeiano, Palacios, \& Mengod, 1992; Kia, Brisorgueil, Hamon, Calas, \& Vergé, 1996; Kia et al., 1996; Maeda et al., 2001). In the neocortex the 5-HT $\mathrm{HT}_{1 \mathrm{~A}}$ heteroreceptor is expressed mainly on pyramidal glutamatergic neurons, and in pyramidal and granular neurons of the hippocampus (Pompeiano et al., 1992). Heteroreceptors are also found in the raphe nuclei, although in low density in comparison to 5- $\mathrm{HT}_{1 \mathrm{~A}}$ autoreceptors in the raphe (Gozlan, El Mestikawy, Pichat, Glowinski, \& Hamon, 1983; Verge et al., 1985; Riad et al., 2000).

Stimulation of 5- $\mathrm{HT}_{1 \mathrm{~A}}$ receptors inhibits nerve cell firing via membrane hyperpolarisation consequent to activation of a pertussis toxin-sensitive $G$ proteincoupled $\mathrm{K}^{+}$conductance (Andrade, Malenka, \& Nicoll, 1986; De Vivo \& Maayani, 1986; Innis \& Aghajanian, 1987; Hamon et al., 1988; Innis, Nestler, \& Aghajanian, 1988; Chamberlain et al., 1993; Albert, Lembo, Storring, Charest, \& 
Saucier, 1996; Clarke, Yocca, \& Maayani, 1996). In addition, there are a number of differences in other signal transduction cascades between the $5-\mathrm{HT}_{1 \mathrm{~A}}$ autoreceptors and hetereoreceptors. The 5- $\mathrm{HT}_{1 \mathrm{~A}}$ hetereoreceptor, but not the autoreceptor (Clarke et al., 1996; Johnson, Fiorella, Winter, \& Rabin, 1997), couples negatively via $\mathrm{Gi} / \mathrm{Go}$ proteins to adenylate cyclase. In this case, stimulation inhibits adenylate cyclase, thereby depressing cyclic adenosine monophosphate (cAMP), and in turn, decreasing the activity of protein kinase A (PKA). This cascade has the effect of inhibiting PKA phosphorylation of TPH the enzyme responsible for catalysing the rate-limiting step in serotonin synthesis. Interestingly however, $5-\mathrm{HT}_{1 \mathrm{~A}}$ receptor agonists have been reported to inhibit adenylate cyclase activity, supposedly via $5-\mathrm{HT}_{1 \mathrm{~A}}$ autoreceptors, in raphe from postmortem human brain (Palego et al., 1999; Marazziti et al., 2002). Furthermore, $5-\mathrm{HT}_{1 \mathrm{~A}}$ autoreceptors alone reduce a $\mathrm{Ca}_{2}{ }^{+}$conductance, which contributes to the negative effects of 5- $\mathrm{HT}_{1 \mathrm{~A}}$ autoreceptor stimulation on cell firing of 5-HT neurons (Andrade \& Nicoll, 1987; Sprouse \& Aghajanian, 1987; Ropert, 1988; Sprouse \& Aghajanian, 1988). Therefore, the two subtypes of 5- $\mathrm{HT}_{1 \mathrm{~A}}$ receptors have functional differences depending on their neuronal location.

Ligands for the 5- $\mathrm{HT}_{1 \mathrm{~A}}$ receptor have been developed to identify the receptor in the brain and study its functions. As an exemplar, the selective 5- $\mathrm{HT}_{1 \mathrm{~A}}$ receptor agonist 8-Hydroxy-2-(di-n-propylamino)tetralin (8-OH-DPAT) has been extensively used to investigate the functional status of the $5-\mathrm{HT}_{1 \mathrm{~A}}$ receptor (Hjorth, Carlsson, Lindberg, \& Sanchez, 1982; Hjorth, 1985; Hillegaart, 1991). The selectivity of 8-OH-DPAT is confirmed by the complete inhibition of its effects by selective 5- $\mathrm{HT}_{1 \mathrm{~A}}$ antagonists, such as WAY100635 and the older and less selective WAY100135 (Gozlan et al., 1983; Adell, Carceller, \& Artigas, 1993; Bosker, Donker, Klompmakers, Kurata, \& Westenberg, 1994; Forster et al., 1995; Davidson \& Stamford, 1995). Moreover, it is evident that low doses of 8-OHDPAT preferentially target the 5- $\mathrm{HT}_{1 \mathrm{~A}}$ autoreceptor over the heteroreceptor (Hjorth \& Magnusson, 1988; Hoyer, Hannon, \& Martin, 2002). Selective 5-HT $1 \mathrm{~A}$ agonists, including 8-OH-DPAT, have been shown to be more potent when applied onto 5-HT neurons, and hence activate autoreceptors, than when they are applied onto non-5-HT neurons where they activate heteroreceptors (Blier, De Montigny, \& Chaput, 1987; Blier \& De Montigny, 1990). A possible molecular 
basis for the autoreceptor selectivity of $8-\mathrm{OH}-\mathrm{DPAT}$ is the large $5-\mathrm{HT}_{1 \mathrm{~A}}$ receptor reserve for $5-\mathrm{HT}_{1 \mathrm{~A}}$ agonists found in the raphe nuclei, in comparison to cortical and limbic areas (Meller, Goldstein, \& Bohmaker, 1990; Cox, Meller, \& Waszczak, 1993; Jolas et al., 1995). It is also possible to describe receptors such as the $5-\mathrm{HT}_{1 \mathrm{~A}}$ as existing in several conformational states, including 'high-affinity' and 'low-affinity' states, with agonists, such as 8-OH-DPAT, binding preferentially to certain states (Samama, Cotecchia, Costa, \& Lefkowitz, 1993). In this way, an increased ratio of high-affinity to low-affinity sites in the raphe nuclei would provide an explanation for 8-OH-DPAT having greater efficacy in the raphe compared to the postsynaptic areas such as the hippocampus (Rabiner, Bhagwagar, Gunn, Cowen, \& Grasby, 2004).

\section{MDMA-induced Deficits}

As outlined previously, MDMA abuse produces persistent cognitive impairments and mood disturbances, and increases the risk of developing psychological disorders. Evidence suggests that these long-term impairments are associated with neurochemical deficits induced by MDMA abuse. These deficits are primarily produced in the 5-HT system, as would be expected given the preferential effect MDMA has on the 5-HT system in comparison to other neurotransmitter systems. Time-course studies reveal two phases of MDMAinduced 5-HT deficits in rats: a rapid acute phase and a long-term phase (Stone, Merchant, Hanson, \& Gibb, 1987; Schmidt, 1987). During the first few hours following MDMA administration, brain tissue 5-HT is extensively depleted and TPH is largely inactive. Twenty-four hours later, tissue 5-HT levels recover to normal although TPH activity remains diminished. The long-term phase, beginning one week later and lasting for months, is characterised by tissue 5-HT depletion (Colado, Murray, \& Green, 1993), sustained inactivation of TPH (Stone, Johnson, Hanson, \& Gibb, 1989), reductions in 5-HIAA (Colado \& Green, 1994), and reductions in serotonin transporter (SERT) binding (Battaglia, Yeh, \& De Souza, 1988; Scanzello, Hatzidimitriou, Martello, Katz, \& Ricaurte, 1993; O’Shea et al., 2006). Additionally, there is decreased immunoreactive 5-HT in fine axons and terminals in forebrain areas along with morphological abnormalities of 5-HT 
axons and terminals (O’Hearn, Battaglia, De Souza, Kuhar, \& Molliver, 1988; Fischer, Hatzidimitriou, Wlos, Katz, \& Ricaurte, 1995).

Numerous studies have explored the functional impact on the serotonin system of these MDMA-induced deficits. The overall finding is that MDMA exposure can cause reductions in the 5-HT response to stimuli that normally evoke a considerable response. Matuszewich, Filon, Finn and Yamamoto (2002) found that rats pretreated with MDMA showed a blunted 5-HT response to an immobilisation stress test in comparison to controls, as measured by microdialysis measures of synaptic overflow in 5-HT terminal regions. Similarly, Series, Cowen and Sharp (1994) and Shankaran and Gudelsky (1999) found that MDMA pretreatment markedly reduced the 5-HT response (by $45 \%$ in the frontal cortex and $55 \%$ in the striatum respectively) to the potent 5-HT releaser fenfluramine. Stimulating the 5-HT system with electrical stimulation of the DRN also produced markedly decreased 5-HT synaptic overflow in the frontal cortex, although not in the hippocampus, two weeks after MDMA treatment (Gartside, McQuade, \& Sharp, 1996). Additionally, multiple studies with human and animal subjects have shown that MDMA pretreatment attenuated hormonal responses to neuroendocrine challenges that are likely to be mediated by the serotonergic system (Price, Ricaurte, Krystal, \& Heninger, 1989; Poland, 1990; Poland et al., 1997; Gerra et al., 1998; Gerra et al., 2000; Gouzoulis-Mayfrank, Becker, Pelz, Tuchtenhagen, \& Daumann, 2002; Baumann, Clark, Franken, Rutter, \& Rothman, 2008). As decreased serotonergic neurotransmission has been found to impair a number of aspects of learning and memory (Altman, Nordy, \& Ogren, 1984; McEntee \& Crook, 1991), these findings suggest that MDMA-induced deficits lead to functional impacts on the 5-HT system that may underlie the cognitive and mood impairments seen with MDMA abuse.

Compelling evidence linking MDMA-induced 5-HT deficits to cognitive impairments has been found in human subjects. Recreational users (greater than 25 exposures) were seen to have significantly lower levers of cerebrospinal fluid (CSF) 5-HIAA than control subjects (McCann, Ridenour, Shaham, \& Ricaurte, 1994; McCann et al., 1999) and correlations between impairments and levels of CSF 5-HIAA have been found (Bolla, McCann, \& Ricaurte, 1998), indicating a role of 5-HT deficits. Furthermore, neuroimaging studies have found lower 
densities of SERT binding sites in MDMA users that correlate with previous MDMA use and indicate structural changes to 5-HT neurons that may relate to cognitive and mood impairments (McCann, Szabo, Scheffel, Dannals, \& Ricaurte, 1998; McCann et al., 2008). For instance, patients with unipolar major depression have been reported to have significantly reduced SERT binding density (Malison et al., 1998).

These persistent MDMA-induced 5-HT deficits were originally thought to be the result of neurotoxicity - the loss of 5-HT terminals, projections and cells. In an ongoing debate, researchers have recently challenged this view on a number of fronts. Baumann (2007) for instance, argues that methods used to detect 5-HT nerve fibres, such as autoradiography, may be too insensitive to detect fibres that are still present, albeit markedly reduced in the TPH biomarker. Additionally, studies show that MDMA-induced reductions in 5-HT levels and SERT binding eventually recover (Battaglia et al., 1988; Scanzello et al., 1993), suggesting the possibility that 5-HT terminals are not destroyed (Buchert et al., 2006; Brennan \& Schenk, 2006).

To further this debate, a number of studies have compared the effects of MDMA with those of the archetypal 5-HT neurotoxin 5,7-DHT as a positive control. In these studies 5,7-DHT produces a profile of neuronal and glial responses that is consistent with neurotoxic damage, whereas MDMA does not (Xie et al., 2006; Wang, Baumann, Dersch, \& Rothman, 2007; Baumann et al., 2007). While both substances deplete brain tissue 5-HT, their actions differ in other key respects. The first is in measures of reactive gliosis - a marker of CNS damage characterised by hypertrophy of astrocytes and increase in glial fibrillary acidic protein (GFAP) (reviewed by O'Callaghan \& Sriram, 2005). Established neurotoxins such as 5,7-DHT increase the levels of GFAP in rodent CNS, indicating this protein can be used as a sensitive marker of neuronal damage (O’Callaghan, Jensen, \& Miller, 1995; O’Callaghan \& Sriram, 2005). Pubill et al. (2003) found no increase in GFAP expression with a MDMA dosing regime (20 $\mathrm{mg} / \mathrm{kg}$ i.p. twice daily for 4 days) that depletes 5-HT. Bai, Jones, Lau and Monks (2001) also failed to find increased GFAP expression in rats after $10 \mathrm{mg} / \mathrm{kg}$ s.c. MDA. Thus MDMA does not exhibit the same reactive gliosis pattern of neuronal damage as the established neurotoxin 5,7-DHT. 
The second respect in which MDMA differs from 5,7-DHT is in effects on the SERT protein. It is established that 5,7-DHT decreases SERT protein binding and expression (Wang, Baumann, Xu, \& Rothman, 2004; Wang, Baumann, Xu, Morales, \& Rothman, 2005). Conversely, administration of high-dose MDMA reduces SERT binding but does not alter the expression of SERT as indicated by SERT mRNA levels and immunohistochemistry (Wang et al., 2004; Wang et al., 2005), even when, for example, binding is reduced by $82 \%$ (Wang et al., 2005). This raises the question of what effect MDMA has on the SERT protein. Earlier studies found no changes in the distribution of SERT protein between the plasma membrane and cytoplasmic areas following MDMA administration (Wang et al., 2004; Wang et al., 2005). However Xie et al. (2006) and Kivell, Day, Bosch, Schenk and Miller (2010) have since questioned the specificity of the SERT antibody used in these studies, and recent research reveals that SERT proteins are down-regulated from the cell membrane to intracellular vesicles following MDMA administration (Kivell et al.). Furthermore, recent research with refined methods has also shown a profound reduction of SERT gene expression in rats due to MDMA (Biezonski \& Meyer, 2010). Although this result appears to coalesce the effects of MDMA and 5,7-DHT, the decrease in SERT immunoreactivity found by Biezonski and Meyer was accompanied by only a minor decrease in vesicular monoamine transporter 2 (VMAT-2) protein levels, suggesting that MDMA-induced reductions in SERT are related to a downregulation phenomenon and are not necessarily dependent on neurotoxicity.

Another factor in this debate is that some studies have shown MDMAinduced 5-HT neurotoxicity through conventional markers of cell death (Commins et al., 1987; Jensen et al., 1993). These discrepancies may be explained by dosage differences, as such studies are likely to have used very high doses of MDMA (cumulatively ranging from 80 to $600 \mathrm{mg} / \mathrm{kg}$ ) that cause nonspecific damage beyond 5-HT neurons and their projections (Baumann et al., 2007). Because of this, the evident neurotoxicity could be linked to other causal factors such as excessive sympathetic activation, hyperthermia and oxidative stress (Baumann et al., 2007; Puerta, Hervias, \& Aguirre, 2009).

In light of the findings of recovery and the largely non-neurotoxic profile of MDMA, the explanation of MDMA-induced 5-HT deficits that is most consistent 
with available data is that they are due to persistent adaptive changes in protein function or gene expression. Evidence of such plastic neuroadaptive changes to repeated MDMA administration have been shown in the 5-HT system. The SERT and VMAT-2 expression results of Biezonski and Meyer (2010) confirm that the serotonergic neurons of the DRN and MRN undergo major neuroadaptations following high-dose MDMA treatment. Additionally, Aguirre, Frechilla, GarciaOsta, Lasheras and Del Rio (1997) found an increase in 5- $\mathrm{HT}_{1 \mathrm{~A}}$ receptor binding in the rat frontal cortex one week following repeated MDMA administration, correlated with enhanced 5-HT $1 \mathrm{~A}$ mRNA expression. Such neuroadaptations may underlie the cognitive and mood impairments seen following MDMA abuse.

The nature of MDMA-induced neuroadaptations in the 5-HT system can be explored further by considering mechanisms that regulate 5-HT synthesis, as a notable aspect of MDMA-induced 5-HT deficits is a reduction in synthesis. 5-HT synthesis is primarily governed by protein levels and activity of the rate-limiting enzyme TPH (Fernstrom \& Wurtman, 1971) and MDMA has been repeatedly shown to produce long-term reductions in TPH activity (Stone et al., 1987; Schmidt, 1987; Bonkale \& Austin, 2008). Therefore, the long-term reductions in TPH activity are likely to be a critical factor in MDMA-induced 5-HT deficits. These reductions are not thought to be caused directly by MDMA, as MDMA has no effect on TPH in vitro (Capela et al., 2009). Rather, as MDMA-induced TPH inhibition is prevented by calcium channel blockers (Johnson et al., 1992), reductions in TPH protein and activity are strongly associated with 5-HT cell firing. 5-HT nerve impulse control is governed by $5-\mathrm{HT}_{1 \mathrm{~A}}$ autoreceptors, the activation of which has been reliably shown to inhibit 5-HT cell firing in the raphe nuclei and to reduce 5-HT synthesis and release in the raphe nuclei and in 5-HT terminal areas (Hjorth et al., 1982; Sprouse \& Aghajanian, 1987; Hamon et al., 1988; Sprouse \& Aghajanian, 1988; Hjorth \& Magnusson, 1988; Blier \& De Montigny, 1990; Bonvento, Scatton, Claustre, \& Rouquier, 1992; Adell et al., 1993; Kreiss \& Lucki, 1994). In particular, studies have shown that 5-HT 1A agonists applied directly to the DRN and MRN results in a decrease in 5-HT synthesis in terminal areas as measured by estimates of the in vivo rate of TPH activity (Hjorth \& Magnusson, 1988; Hillegaart, Hjorth, \& Ahlenius, 1990). Therefore, the $5-\mathrm{HT}_{1 \mathrm{~A}}$ autoreceptor can regulate 5-HT synthesis, and hence might 
mediate a key deficit produced by MDMA. It follows that functional changes in the $5-\mathrm{HT}_{1 \mathrm{~A}}$ receptor would have a pronounced impact on the 5-HT system, and the cognitive, learning and mood processes reliant on 5-HT functioning.

\section{Neuroadaptations in the $5-\mathrm{HT}_{1 \mathrm{~A}}$ receptor}

A number of studies have found neuroadaptive changes in the sensitivity of the 5-HT $\mathrm{HA}_{1 \mathrm{~A}}$ autoreceptor produced by psychostimulants including MDMA. In rats treated with cocaine (15 mg/kg i.p. for 7 days) the inhibitory response of DRN 5HT neurons to an 8-OH-DPAT challenge was increased, indicating enhanced sensitivity of the 5- $\mathrm{HT}_{1 \mathrm{~A}}$ autoreceptors (Cunningham, Paris, \& Goeders, 1992). Repeated treatment with amphetamine ( $5 \mathrm{mg} / \mathrm{kg}$ i.p. twice daily for 6 days) also enhanced 5- $\mathrm{HT}_{1 \mathrm{~A}}$ sensitivity, as indicated by increased $\left[{ }^{3} \mathrm{H}\right]-8-\mathrm{OH}-\mathrm{DPAT}$ binding in the DRN (Bonhomme, Cador, Stinus, Le Moal, \& Spampinato, 1995). With MDMA, Renoir et al. (2008) demonstrated that MDMA pretreated mice (20 $\mathrm{mg} / \mathrm{kg}$, twice daily for four days) had a significantly greater sensitivity to the 5$\mathrm{HT}_{1 \mathrm{~A}}$ agonist ipsapirone, as measured by greater inhibition of DRN 5-HT neuron firing. The authors also found that the spontaneous in vitro firing of mice DRN 5HT neurons was significantly reduced four weeks after MDMA treatment. These findings are indicative of long-term MDMA-induced changes that increase the sensitivity of the 5- $\mathrm{HT}_{1 \mathrm{~A}}$ autoreceptor. This increase in sensitivity can be termed 'supersensitisation'.

Further evidence of sensitivity increases in the 5- $\mathrm{HT}_{1 \mathrm{~A}}$ autoreceptor comes from investigations into the hypothermic response to $5-\mathrm{HT}_{1 \mathrm{~A}}$ agonists. This hypothermic effect is thought to be $5-\mathrm{HT}_{1 \mathrm{~A}}$-mediated, although there is debate in the literature over the contribution of heteroreceptors and autoreceptors. It has been shown that direct application of 8-OH-DPAT into the DRN produced the hypothermic response in rats and the effect was inhibited by selective $5-\mathrm{HT}_{1 \mathrm{~A}}$ antagonists (Higgins, Bradbury, Jones, \& Oakley, 1988; Hillegaart, 1991). Additionally, Rusyniak et al. (2007) found that microinjections of WAY 100635 into the rostral raphe pallidus (rRP) significantly attenuated 8-OH-DPAT (0.2 $\mathrm{mg} / \mathrm{kg}$ i.p.)-elicited hypothermia, suggesting the role of 5-HT $1 \mathrm{~A}$ autoreceptors on 5-HT neurons in the rRP (Helke, Capuano, Tran, \& Zhuo, 1997). However, the buspirone analogue BMY 7378, which is a high-efficiency agonist at 5- $\mathrm{HT}_{1 \mathrm{~A}}$ 
receptors in the DRN but a low-efficiency agonist in terminal areas, failed to produce a hypothermic effect when directly infused in to the DRN (O'Connell, Sarna, \& Curzon, 1992). Although the mechanisms behind thermoregulation are complex, the available evidence suggests that 8-OH-DPAT produces its hypothermic response at least in large part via 5-HT HA $_{\text {A }}$ autoreceptors. 8-OH-DPAT was found to enhance the hypothermic response in mice that had been treated with MDMA four weeks previously (Bill, Knight, Forster, \& Fletcher, 1991). Aguirre et al. (1998) also found a potentiated hypothermic response to 8-OH-DPAT in rats one week after a single administration (30 mg/kg i.p.) of MDMA. Therefore, there is evidence that MDMA pretreatment produces sensitivity changes in the $5-\mathrm{HT}_{1 \mathrm{~A}}$ receptors, resulting in an enhanced hypothermic response, through a putative 5$\mathrm{HT}_{1 \mathrm{~A}}$ autoreceptor mediated mechanism.

Another means of investigating the functional status of the $5-\mathrm{HT}_{1 \mathrm{~A}}$ autoreceptor is through its effects on 5-HT synthesis. Changes in sensitivity of the $5-\mathrm{HT}_{1 \mathrm{~A}}$ autoreceptor can be assessed by in vivo measurements of serotonin synthesis, as this is mediated by $5-\mathrm{HT}_{1 \mathrm{~A}}$ autoreceptor activation. Serotonin synthesis can be measured in vivo by inhibiting the reaction from 5-HTP to 5-HT, causing the accumulation of 5-HTP in the cytoplasm that acts as a measure of the rate of 5-HT synthesis (Carlsson, Davis, Kehr, Lindqvist, \& Atack, 1972). Studies with ethanol, a substance also liable to abuse and to cause long-term impairments in learning and cognition, implicate supersensitised 5- $\mathrm{HT}_{1 \mathrm{~A}}$ receptors as involved in impairments through measures of 5-HT synthesis. Kelaï et al. (2008) and Esteban, Moranta, Sastre-Coll, Miralles and Garcia-Sevilla (2002) found that inhibition of 5-HTP accumulation was significantly more pronounced in ethanol pretreated mice. Both of these results indicate supersensitisation of the autoreceptor following ethanol pretreatment, resulting in greater inhibition of 5HT synthesis.

\section{The Current Study}

As previously described, MDMA abuse causes persistent deficits in the 5HT system leading to impairments in cognition and mood. The $5-\mathrm{HT}_{1 \mathrm{~A}}$ receptor has been shown to be implicated in these deficits, possibly by way of neuroadaptations that impact on 5-HT neuron functioning. The aim of this thesis 
is to investigate changes in 5- $\mathrm{HT}_{1 \mathrm{~A}}$ autoreceptor sensitivity following repeated, high-dose MDMA administration. An autoreceptor selective dose of 8-OH-DPAT can be used to test for neuroadaptive changes in 5- $\mathrm{HT}_{1 \mathrm{~A}}$ autoreceptor sensitivity following MDMA pretreatment. The sensitivity changes can be measured in two ways: the effect on 5-HT synthesis, and the hypothermic response. With respect to these two measures of receptor functioning, it is hypothesised that MDMA pretreatment will increase the sensitivity of the $5-\mathrm{HT}_{1 \mathrm{~A}}$ autoreceptor, as realised in two ways. First, it is hypothesised that MDMA pretreated rats will accumulate significantly less 5-HTP following 8-OH-DPAT administration in comparison to saline controls. Second, it is hypothesised that MDMA pretreated rats will have a potentiated hypothermic response to 8-OH-DPAT administration in comparison to saline controls. Furthermore, it is theorised that the MDMA-induced supersensitisation of the 5- $\mathrm{HT}_{1 \mathrm{~A}}$ autoreceptor is critical in the expression of longterm serotonergic deficits, through a sensitised down-regulation of 5-HT synthesis and release. This sensitised down-regulation is thought to lead to the cognitive and mood impairments seen with MDMA abuse.

This study is unique because it is the first to investigate MDMA-induced changes in the sensitivity of the 5- $\mathrm{HT}_{1 \mathrm{~A}}$ autoreceptor using 5-HTP accumulation in vivo with an autoreceptor selective $5-\mathrm{HT}_{1 \mathrm{~A}}$ agonist. Previous investigations of 5-HT $\mathrm{HA}_{1 \mathrm{~A}}$ autoreceptor sensitivity have used the hypothermic effect (Renoir et al., 2008), but not a 5-HTP accumulation measure of 5-HT synthesis. Additionally, previous studies (for example O'Shea et al., 2006) that have measured 5-HTP accumulation following MDMA pretreatment have not done so in the context of a $5-\mathrm{HT}_{1 \mathrm{~A}}$ receptor agonist and therefore are unable to associate changes in $5-\mathrm{HT}_{1 \mathrm{~A}}$ sensitivity to MDMA-induced deficits.

It is hoped that the results of the experiments will further clarify the mechanisms behind cognitive and mood impairments resulting from MDMA abuse. Greater fundamental knowledge of these mechanisms will inform future research towards the development of novel pharmaceutical therapies to improve the wellbeing of those suffering the effects of MDMA, and other psychostimulants abuse. 


\section{Method}

\section{Subjects}

The subjects were male Sprague-Dawley rats weighing 172-226g. The rats were from a population bred in the vivarium at Victoria University of Wellington.

Rats were housed in a 12 hour light-dark cycle, with temperature $\left(21^{\circ} \mathrm{C}\right)$ and humidity (77\%) controlled. Tests were conducted during the light portion of the cycle, between 08:00 and 17:00 hours. Food and water were available ad libitum except during the six MDMA administration hours in Experiments 2 and $2 \mathrm{~b}$.

The Victoria University of Wellington Institutional Animal Ethics Committee has approved all protocols used in the experiments.

\section{Experimental Procedures}

Using 5-HTP as a marker of 5-HT 1 sensitivity

Changes in sensitivity of the 5- $\mathrm{HT}_{1 \mathrm{~A}}$ autoreceptor were assessed by in vivo measurement of serotonin synthesis using the 5-HTP accumulation method with 3-hydroxybenzylhydrazine dihydrochloride (NSD-1015) (Carlsson et al., 1972). NSD-1015 is a potent inhibitor of the aromatic amino acid decarboxylase enzyme that catalyses the decarboxylation reaction of 5-HTP to 5-HT. By inhibiting the decarboxylase enzyme, NSD-1015 causes the accumulation of 5-HTP in the cytoplasm. As 5-HTP is formed by the hydroxylation of L-tryptophan by TPH, NSD-1015 acts as a measure of TPH activity.

Measurement of 5-HTP accumulation can be regarded as a measure of 5-HT synthesis because the conversion involves a single compartment system (Tozer, Neff, \& Brodie, 1966). As activation of the 5-HT $1 \mathrm{~A}$ autoreceptor inhibits 5-HT synthesis, and therefore reduces the rate of TPH, the 5-HTP accumulated in the presence of a 5- $\mathrm{HT}_{1 \mathrm{~A}}$ agonist acts as a measure of the sensitivity of the autoreceptor. An increase in the sensitivity of the autoreceptor, as hypothesised in the current experiments, would result in a down-regulation of 5-HT synthesis and hence TPH activity, leading to less 5-HTP being available for accumulation and 
measurement. The selective 5- $\mathrm{HT}_{1 \mathrm{~A}}$ agonist $8-\mathrm{OH}-\mathrm{DPAT}$ is used in the current experiments to activate the autoreceptor prior to NSD-1015 administration. The decarboxylase inhibition method is necessary as otherwise there would not be a sufficient concentration of 5-HTP to allow measurement given that the conversion of 5-HTP to 5-HT is immediate and almost total (Carlsson, Bédard, Lindqvist, \& Magnusson, 1972).

\section{Determination of 5-HTP, 5-HT and 5-HIAA}

Thirty minutes following NSD-1015 administration rats were rendered unconscious by $\mathrm{CO}_{2}$, decapitated and their brains rapidly extracted. The brains were sliced using an ice-cold stainless steel brain block following the procedures of Heffner, Hartman and Seiden (1980). The frontal cortex, striatum and hippocampus were dissected, placed in labelled vials, weighed, and then stored at $-80^{\circ} \mathrm{C}$ until analysed.

Analysis to determine tissue concentrations of neurochemicals was performed by High Performance Liquid Chromatography with Electrochemical Detection (HPLC-ED), following procedures outlined by Hamon et al. (1988) and Kelaï et al. (2008). Tissue samples were removed from the freezer, homogenised in 10 volumes of $0.1 \mathrm{~N}$ perchloric acid and centrifuged at $12,000 \mathrm{~g}$ for $30 \mathrm{~min}$ at $4^{\circ} \mathrm{C}$. The supernatant was filtered and injected into the HPLC-ED system (Agilent 1100 series). The injection volume was $5 \mu \mathrm{L}$ for the striatum and $20 \mu \mathrm{l}$ for the other regions. Constituent chemicals were separated using a C18 reversed phase column $(150 \times 4.6 \mathrm{~mm}, 5 \mu \mathrm{m}$ particle size; Eclipse XDB-C18, Agilent, USA). The mobile phase consisted of $\mathrm{NaH}_{2} \mathrm{PO}_{4}(75 \mathrm{mM})$, octane-1-sulphonic acid (1.7 mM), EDTA $(0.25 \mathrm{mM})$, triethylamine $(100 \mu \mathrm{L} / \mathrm{L})$ and acetonitrile $(10 \%)$, and was adjusted to $\mathrm{pH} 3$ with phosphoric acid. The flow rate was $1 \mathrm{ml} / \mathrm{min}$. Detection was performed using a coulometric detector (Coulochem III, ESA, USA). The guard cell potential was set at $450 \mathrm{mV}$ and the analytical cell potentials at -175 and 325 $\mathrm{mV}$. Working external standards (500 - $15.125 \mathrm{ng} / \mathrm{ml}$ in $0.1 \mathrm{~N}$ perchloric acid) were prepared daily from standard stock solutions. Chromatograms were acquired with ChemStation software (Agilent, USA). Peak heights of standards and samples were measured, and the concentrations in samples were calculated from 
the regression curves obtained from standards. Concentrations are expressed as ng per mg of tissue.

\section{Using hypothermia as a marker of 5-HT $T_{1 A}$ sensitivity}

The hypothermic response to 8-OH-DPAT (Goodwin, De Souza, Green, \& Heal, 1987), mediated by a putative 5- $\mathrm{HT}_{1 \mathrm{~A}}$ autoreceptor mechanism, was used to provide an indicator of $5-\mathrm{HT}_{1 \mathrm{~A}}$ autoreceptor sensitivity. A lubricated digital rectal thermometer probe (Surgipack Digital Thermometer, Code 6344) was inserted 2 $\mathrm{cm}$ into the rectum immediately prior to administration of 8-OH-DPAT to establish a baseline, and 30 minutes post administration. Rats were lightly restrained by hand until the temperature stabilised (no longer than 30 seconds at any time), using a method adapted from Ho et al. (2004). All readings were taken in the temperature controlled $\left(21^{\circ} \mathrm{C}\right)$ home room. Previous studies have found the peak hypothermic effect at this 30 minute time point post administration (Hjorth, 1985).

\section{Experiment 1 - Method validation}

A range of low, autoreceptor-selective doses of the 5- $\mathrm{HT}_{1 \mathrm{~A}}$ agonist $8-\mathrm{OH}-$ DPAT doses were administered, together with NSD-1015, to confirm 8-OHDPAT's effect on 5-HT synthesis and the general effects of NSD-1015. No MDMA pretreatment was performed in this experiment.

A total of 35 drug naïve rats received one of the following doses of 8-OHDPAT: $0.025,0.05,0.1 \mathrm{mg} / \mathrm{kg}$ s.c. or saline $(0.9 \% \mathrm{NaCl}, 1 \mathrm{ml} / \mathrm{kg}$, s.c. $)$. Thirty minutes after 8-OH-DPAT administration, NSD-1015 (100 mg/kg i.p.) was administered, a dose that has been shown to produce complete inhibition of the rate-limiting decarboxylase enzyme (Carlsson et al., 1972). Of those that received saline, there was also a smaller control group $(n=5)$ that did not receive NSD1015 , receiving saline (100 ml/kg i.p.) instead.

Rats were then processed to determine 5-HTP, 5-HT and 5-HIAA levels as described in the experimental procedures. 


\section{Experiment 2 - Effect of MDMA pretreatment on 5-HT ${ }_{1 \mathrm{~A}}$ sensitivity}

In order to test for increased sensitivity of the $5-\mathrm{HT}_{1 \mathrm{~A}}$ autoreceptor following repeated MDMA exposure, a MDMA administration regime of four 10 $\mathrm{mg} / \mathrm{kg}$ i.p. injections spaced two hours apart was chosen, giving a total dose of 40 $\mathrm{mg} / \mathrm{kg}$ i.p. over a 6 hour period. Of a total of 80 rats, 40 received MDMA and 40 received saline. The schedule and dose were chosen because they have been shown to reliably produce significant 5-HT deficits in 5-HT markers (Scanzello et al., 1993; Fischer et al., 1995; Sumnall et al., 2004; Nair \& Gudelsky, 2006; Brennan \& Schenk, 2006), a suppression of MDMA-induced 5-HT response (Shankaran \& Gudelsky, 1999) and a downward shift in the dose-effect curve for MDMA-induced hyperactivity (Brennan \& Schenk, 2006). Additionally, the repeated dosing regimen attempts to approximate the effects of the common practice of sequential dosing ('bumping') often used by human subjects (Parrott, 2001; Sanchez et al., 2004). During this regime the rats were individually housed.

Following MDMA administration, rats were collectively housed in cages of five animals for a period of two weeks. This time period was chosen because deficits in tissue 5-HT and 5-HIAA concentrations, and alterations to 5-HT receptors, have been demonstrated following two weeks (Shankaran \& Gudelsky, 1999; Reneman et al., 2002).

After two weeks, measurement of the sensitivity of the 5-HT $\mathrm{H}_{1 \mathrm{~A}}$ autoreceptor was performed using the 5-HTP accumulation and the hypothermic response methods as described previously. 8-OH-DPAT $(0,0.025,0.05$, or $0.1 \mathrm{mg} / \mathrm{kg} \mathrm{s.c.})$ and NSD-1015 (100 mg/kg i.p.) were administered as in Experiment 1. Rats were then processed to determine 5-HTP, 5-HT and 5-HIAA levels as described in the experimental procedures.

\section{Experiment 2b - Additional 8-OH-DPAT doses}

In response to the results of Experiment 2, further lower doses of 8-OHDPAT were tested (see Results for more details). The procedures of Experiment 2 were repeated with a total of 60 rats, half receiving MDMA pretreatment, and 8OH-DPAT being administered at different doses: $0.00625,0.0125 \mathrm{mg} / \mathrm{kg}$ s.c. 8 OH-DPAT, or saline $(0.9 \% \mathrm{NaCl}, 1 \mathrm{ml} / \mathrm{kg}$, s.c. $)$. 
Of the rats administered saline instead of 8-OH-DPAT, there were also two groups (one MDMA pretreated and one not) that did not receive NSD-1015 and acted as saline controls instead.

\section{Statistical Analyses}

Differences in tissue neurochemical levels and temperature changes between groups were assessed using one-way and two-way analysis of variance (ANOVA), and appropriate post-hoc tests where applicable. GraphPad Prism 5 and SPSS Statistics 18 were used.

\section{Drugs}

\pm MDMA HCl (ESR Ltd, Porirua, New Zealand) was dissolved in saline at the concentration of $10 \mathrm{mg} / \mathrm{ml}$ and injected at a volume of $1 \mathrm{ml} / \mathrm{kg}$ i.p. MDMA purity was examined by gas chromatography and nuclear magnetic resonance spectroscopy, and assessed at greater than $98 \%$.

\pm 8 -OH-DPAT HBr (Tocris, Bristol, UK) was dissolved in saline at the concentration of $0.1 \mathrm{mg} / \mathrm{ml}$, then further diluted to achieve appropriate concentrations; injections were at a volume of $1 \mathrm{ml} / \mathrm{kg}$, s.c.

NSD-1015 (Sigma, Auckland, New Zealand) was dissolved in degassed saline at the concentration of $20 \mathrm{mg} / \mathrm{ml}$ and injected at a volume of $5 \mathrm{ml} / \mathrm{kg}$, i.p.

Drug doses refer to the salt. 


\section{Results}

\section{Experiment 1}

In Figure 1, the effect of NSD-1015 in inhibiting the decarboxylase enzyme is shown through the accumulation of 5-HTP (a), and the effect on 5-HT levels (b) and 5-HIAA levels (c) in the frontal cortex. An unpaired t test revealed that between saline control rats that received NSD-1015 $(M=.11, S D=.02)$ and those that $\operatorname{did} \operatorname{not}(M=.0096, S D=.0006), \mathrm{NSD}-1015$ induced a statistically significant $1061 \%$ increase in 5-HTP tissue levels, $\mathrm{p}<.0001$. This result shows the efficacy of NSD-1015 in inhibiting the decarboxylase enzyme leading to 5-HTP accumulation, and hence supports the validity of this aspect of the experimental method.

It is interesting to note that tissue 5-HT levels were also significantly increased (27\%) by NSD-1015 treatment between 'Saline' rats $(M=.37, S D$ $=.036)$ and those that received NSD-1015 $(M=.47, S D=.05), \mathrm{p}<.01$. Furthermore, NSD-1015 caused a significant 37\% decrease in tissue 5-HIAA levels between 'Saline' rats $(M=.25, S D=.024)$ and those that received NSD$1015(M=.16, S D=.039), \mathrm{p}<.001$.

(a) 5-HTP accumulation

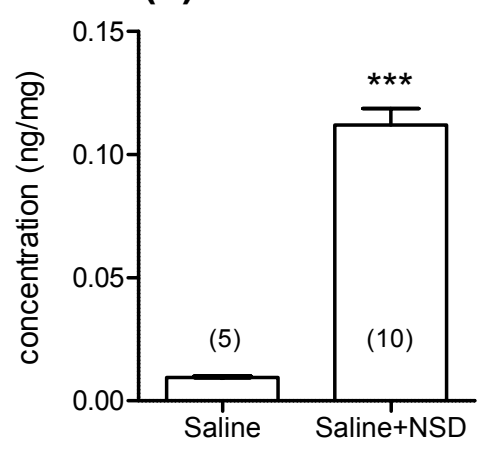

(b) 5 -HT levels

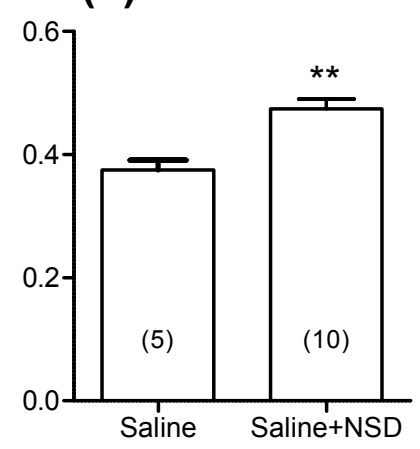

(c) 5-HIAA levels

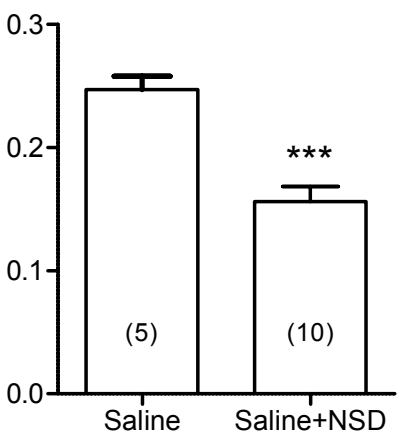

Fig. 1. The effects of NSD-1015 $(100 \mathrm{mg} / \mathrm{kg}$ i.p. $)$ in the frontal cortex on 5-HTP accumulation (a), 5-HT tissue levels (b) and 5-HIAA tissue levels (c) 30 minutes following NSD-1015 administration. Mean values are plotted and error bars 
represent the SEM. Asterisks represent statistical significance from controls that did not receive NSD-1015, with $* * p<.01$ and $* * * p<.001$.

Comparisons of the 5-HT turnover rate between 'Saline' rats $(M=.66, S D$ $=.075)$ and those that received NSD-1015 $(M=.34, S D=.11)$ revealed that the decarboxylase inhibitor induced a 49\% decrease in 5-HT turnover, $\mathrm{p}<.0001$.

Figure 2 shows the effect of 8-OH-DPAT $(0,0.025,0.05$ and $0.1 \mathrm{mg} / \mathrm{kg}$ s.c.) on 5-HTP tissue levels in the frontal cortex (a) and hippocampus (b). For the frontal cortex, a one-way ANOVA revealed a significant main effect of 8-OHDPAT treatment on 5-HTP concentration, $F(3,34)=22.26, p<.0001$. Tukey's post-hoc comparisons of the four doses indicate that the $0.05 \mathrm{mg} / \mathrm{kg}$ dose $(M=$ $0.085, S D=.016)$ and the $0.1 \mathrm{mg} / \mathrm{kg}$ dose $(M=.054, S D=.0065)$ induced significantly lower 5 -HTP accumulation in comparison to saline controls, $\mathrm{p}<.01$ and $\mathrm{p}<.001$ respectively.

In the hippocampus, a one-way ANOVA revealed a significant effect of 8OH-DPAT treatment on 5-HTP concentration, $F(3,34)=21, p<.0001$. Tukey's post-hoc comparisons of the four doses indicate that the $0.1 \mathrm{mg} / \mathrm{kg}$ dose $(M=.1$, $S D=.014)$ induced significantly less 5-HTP accumulation in comparison to saline controls, $\mathrm{p}<.001$. Data for the striatum is not available.

(a) frontal cortex

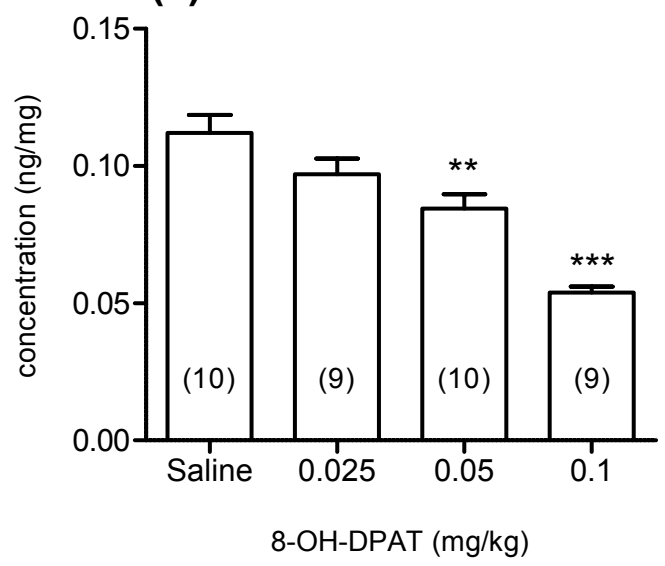

(b) hippocampus

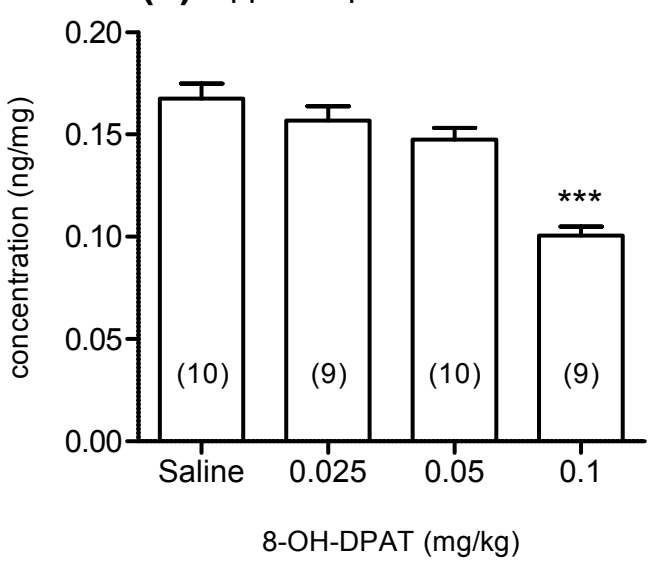


Fig. 2. 5-HTP accumulation (ng/mg) one hour following 8-OH-DPAT treatment (0, 0.025, 0.05 or $0.1 \mathrm{mg} / \mathrm{kg} \mathrm{s.c.)} \mathrm{and} 30$ minutes following NSD-1015 (100 mg/kg i.p.) treatment in the frontal cortex (a) and hippocampus (b). Mean values are plotted and error bars represent the SEM. Asterisks represent statistical significance from saline controls, with $* * \mathbf{p}<.01$ and $* * * \mathbf{p}<.001$.

\section{Experiment 2}

In this experiment, the 8-OH-DPAT doses from Experiment 1 were used to probe the 5-HT $1 \mathrm{~A}$ autoreceptor two weeks following MDMA pretreatment.

Figure 3 shows the effect of 8-OH-DPAT on 5-HTP tissue levels in the frontal cortex (a), striatum (b) and hippocampus (c) between MDMA pretreated rats and saline controls. In the frontal cortex, a two-way ANOVA (pretreatment X 8-OH-DPAT dose) revealed a sole main effect for 8-OH-DPAT dose, $F(3,72)=$ $14, p<.0001$. The interaction between pretreatment and 8-OH-DPAT dose was not significant, $F(3,72)=1.3, p>.05$. There does however appear to be a nonsignificant trend of lower 5-HTP levels in MDMA rats at the $.025 \mathrm{mg} / \mathrm{kg}$ dose of 8-OH-DPAT. In the striatum there was a sole main effect of 8-OH-DPAT dose, $F(3,72)=19.37, p<.0001$. The interaction between pretreatment and 8-OHDPAT dose was not significant, $F(3,72)=.78, p>.05$. In the hippocampus, there was a sole main effect of 8 -OH-DPAT dose, $F(3,72)=13.39, p<.0001$. The interaction between pretreatment and 8-OH-DPAT dose was not significant, $F$ (3, $72)=1.5, p>.05$.

These results indicate that MDMA pretreatment did not lead to 8-OH-DPAT having a more pronounced effect in reducing 5-HTP accumulation levels following decarboxylase inhibition. 
(a) frontal cortex 5-HTP

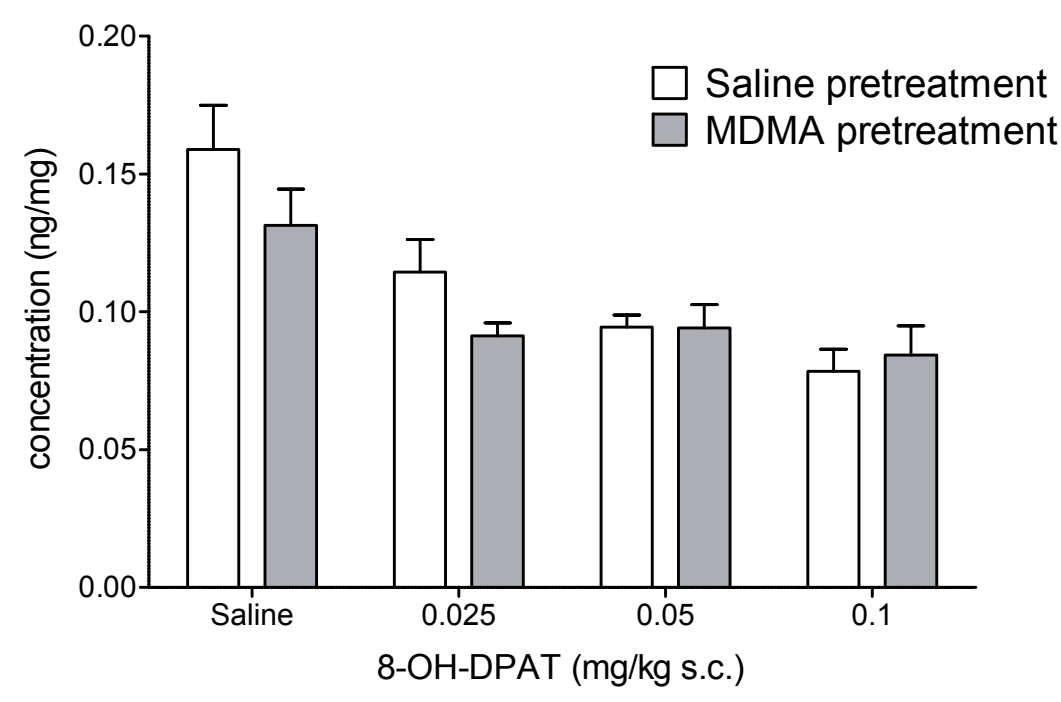

(b) striatum 5-HTP

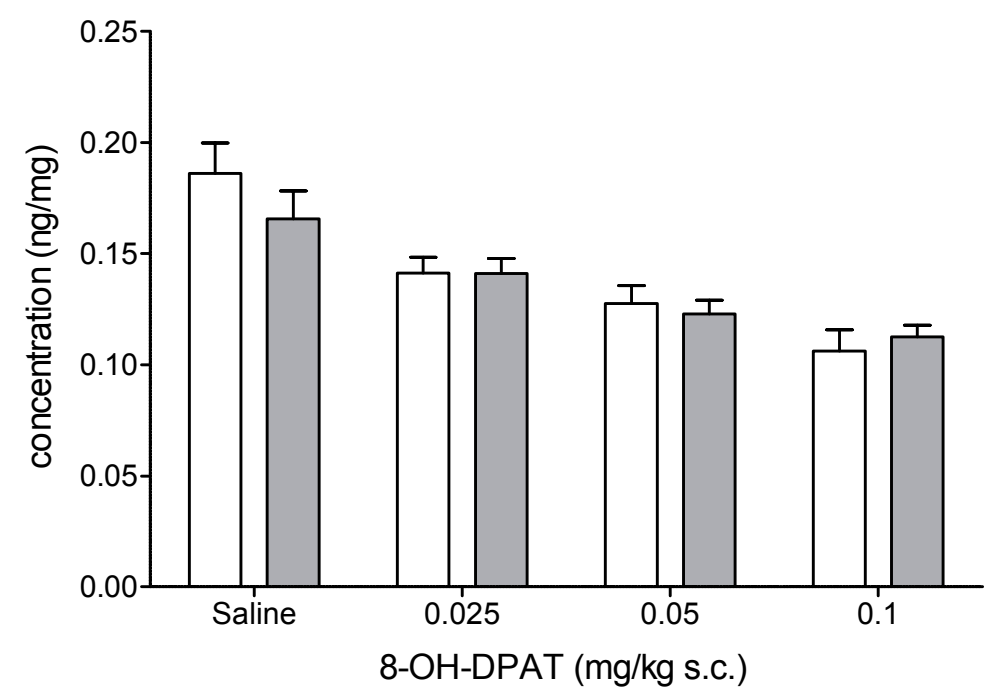

(c) hippocampus 5-HTP

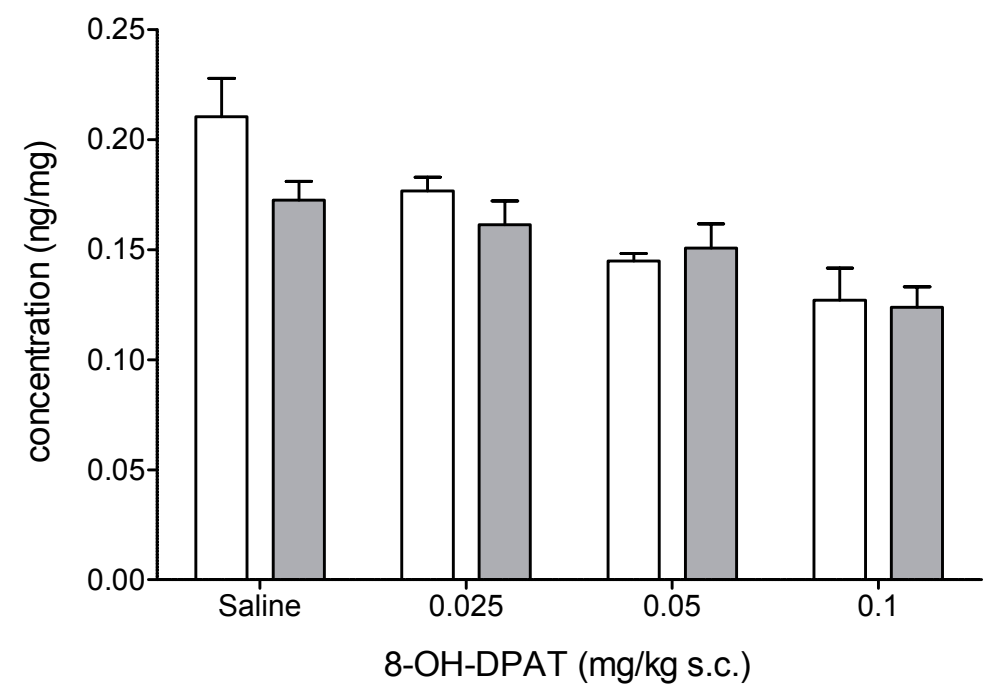


Fig. 3. 5-HTP accumulation in the frontal cortex (a), striatum (b) and hippocampus (c) in rats two weeks following pretreatment with MDMA (4x 10 $\mathrm{mg} / \mathrm{kg}$ i.p.) or saline. To measure 5-HTP accumulation, 8-OH-DPAT (0, 0.025, 0.05, or $0.1 \mathrm{mg} / \mathrm{kg}$ s.c.) was administered, followed 30 minutes later by NSD-1015 (100 $\mathrm{mg} / \mathrm{kg}$ i.p.), and then brains were extracted 30 minutes after NSD-1015. Mean values are plotted and error bars represent the SEM. For all groups, $n=10$.

To determine the effect of MDMA pretreatment in inducing 5-HT deficits, analyses of 5-HT and 5-HIAA tissue levels were performed. Figure 4 shows this analysis for the frontal cortex (a, d), striatum (b, e) and hippocampus (c, f) between MDMA pretreated rats and saline controls. The only significant difference between the groups was found in the hippocampal 5-HT levels. For this region an unpaired $\mathrm{t}$ test revealed that rats that received MDMA pretreatment ( $M$ $=.57, S E M=.025)$ had significantly reduced 5-HT tissue levels than saline controls $(M=.74, S E M=.041), p<.01$. 
(a) frontal cortex 5-HT

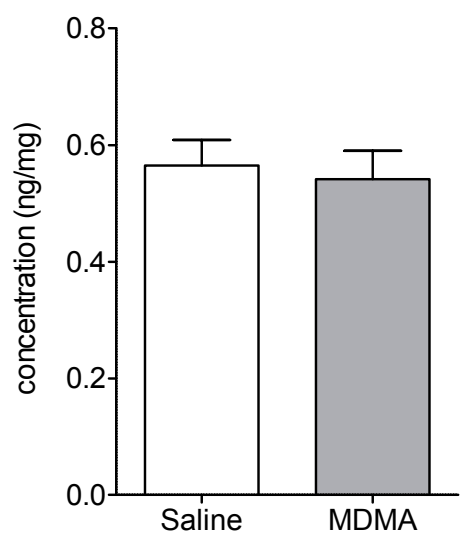

(d) frontal cortex 5-HIAA

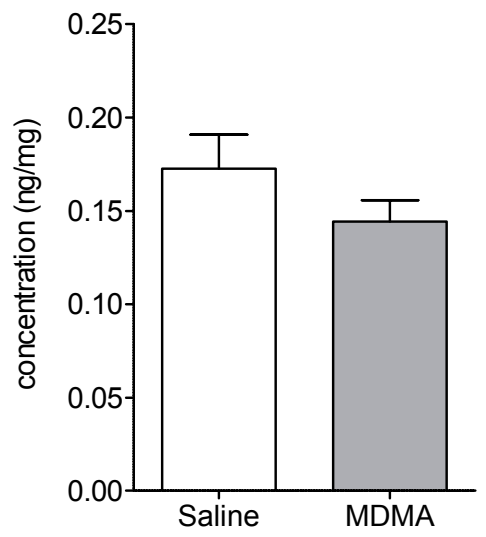

(b) striatum 5-HT

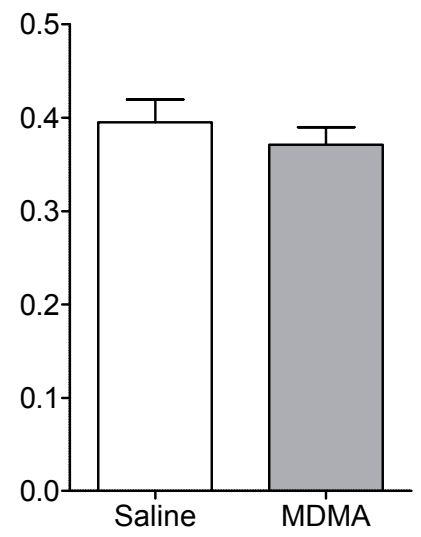

(e) striatum 5-HIAA

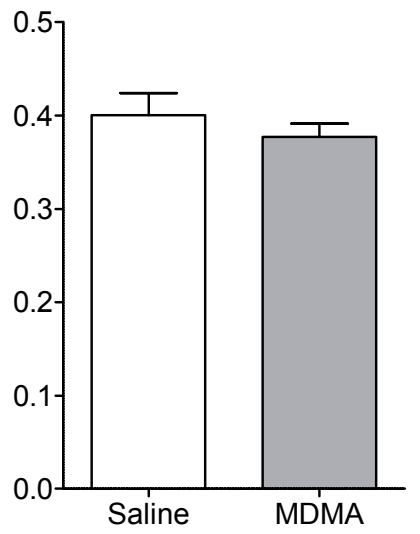

(c) hippocampus 5-HT

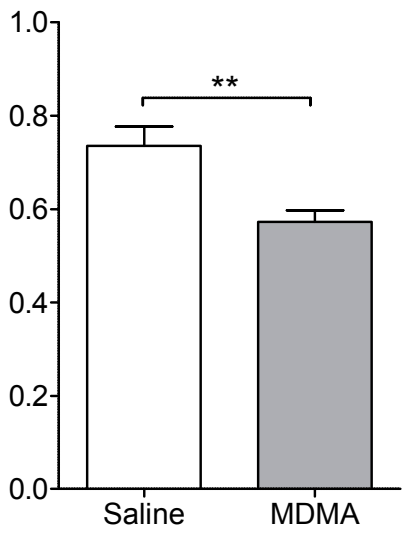

(f) hippocampus 5-HIAA

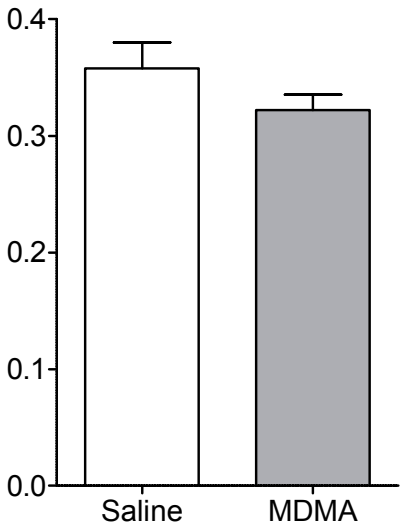

Fig. 4. 5-HT and 5-HIAA tissue levels in the frontal cortex (a, d), striatum (b, e) and the hippocampus (c, $f)$ in rats two weeks following MDMA (4x $10 \mathrm{mg} / \mathrm{kg}$ i.p.) or saline pretreatment, and without 8-OH-DPAT but with NSD-1015 (100 mg/kg i.p.) administration 30 minutes prior to brain extraction. Mean values are plotted and error bars represent the SEM. For all groups, $n=10$. Asterisks represent statistical significance from saline controls, with $* * \mathbf{p}<.01$.

Figure 5 shows the change in core body temperature values for MDMA and saline pretreated rats as a result of 8-OH-DPAT treatment. A two-way ANOVA (pretreatment X 8-OH-DPAT dose) revealed a sole main effect for 8-OH-DPAT dose, $F(3,72)=57, p<.0001$. The interaction between pretreatment and 8-OHDPAT dose was not significant, $F(3,72)=1.6, p>.05$. 


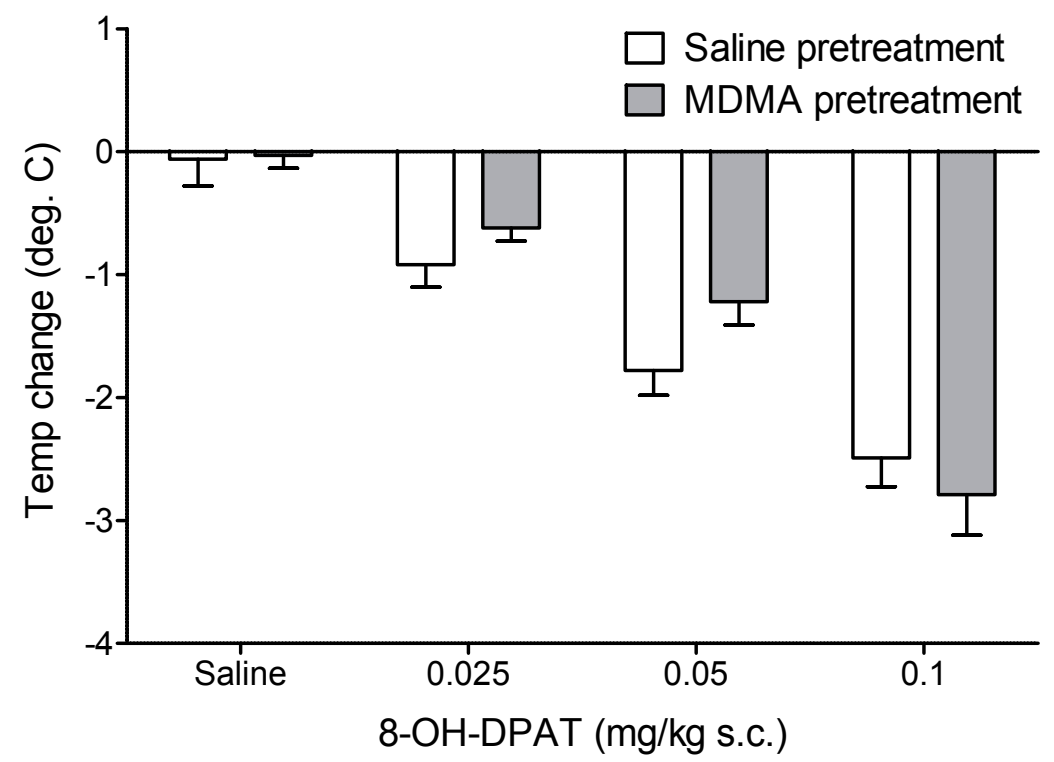

Fig. 5. Change in rectal core body temperature as a result of 8-OH-DPAT treatment for both MDMA (4x $10 \mathrm{mg} / \mathrm{kg}$ i.p.) and saline pretreated rats. Temperature measurements were assessed by rectal probe immediately prior to 8OH-DPAT injection s.c. and 30 minutes post injection. Mean values are plotted and error bars represent the SEM. For all groups, $n=10$.

The results of Experiment 2 suggested that there could be an effect of MDMA pretreatment at lower doses of 8-OH-DPAT. The nonsignificant difference between MDMA and saline groups at the $0.025 \mathrm{mg} / \mathrm{kg}$ 8-OH-DPAT dose, seen most clearly in the frontal cortex (Figure 3a), suggested that lower doses further may elucidate an effect due to MDMA pretreatment. Furthermore, the large difference between the saline pretreatment groups between 8-OH-DPAT doses $0 /$ saline and $0.025 \mathrm{mg} / \mathrm{kg}$ suggested that there was scope for lower doses to complete the dose-response relationship. Experiment $2 \mathrm{~b}$ was performed as an extension to Experiment 2 to test lower doses of 8-OH-DPAT.

\section{Experiment 2b}

In Experiment 2b, two lower doses of 8-OH-DPAT were tested, 0.00625 $\mathrm{mg} / \mathrm{kg}$ and $0.0125 \mathrm{mg} / \mathrm{kg}$. Figure 6 shows the effect of these doses on 5-HTP 
accumulation in the frontal cortex (a), striatum (b) and hippocampus (c) of MDMA and saline pretreated rats.

In the frontal cortex, a two-way ANOVA (pretreatment X 8-OH-DPAT dose) revealed a sole main effect for pretreatment, $F(1,44)=4.1, p<.05$, indicating that MDMA pretreated rats have significantly lower 5-HTP levels across all 8-OH-DPAT doses. The interaction between pretreatment and 8-OHDPAT dose was not significant, $F(2,44)=.55, p>.05$. Bonferroni post-hoc tests found no significant differences between the group means.

In the striatum there was a sole main effect of 8-OH-DPAT dose, $F(2,44)$ $=1.7, p<.01$. The interaction between pretreatment and 8-OH-DPAT dose was not significant, $F(2,44)=1.7, p>.05$. In the hippocampus, there was no significant main effects and the interaction between pretreatment and 8-OHDPAT dose was not significant, $F(3,72)=1.5, p>.05$. 
(a) frontal cortex 5-HTP

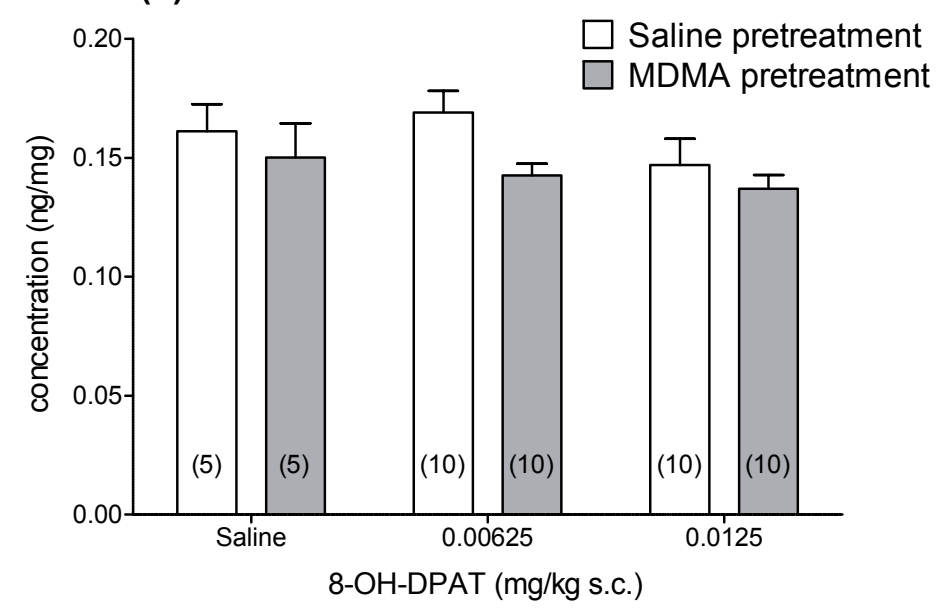

(b) striatum 5-HTP

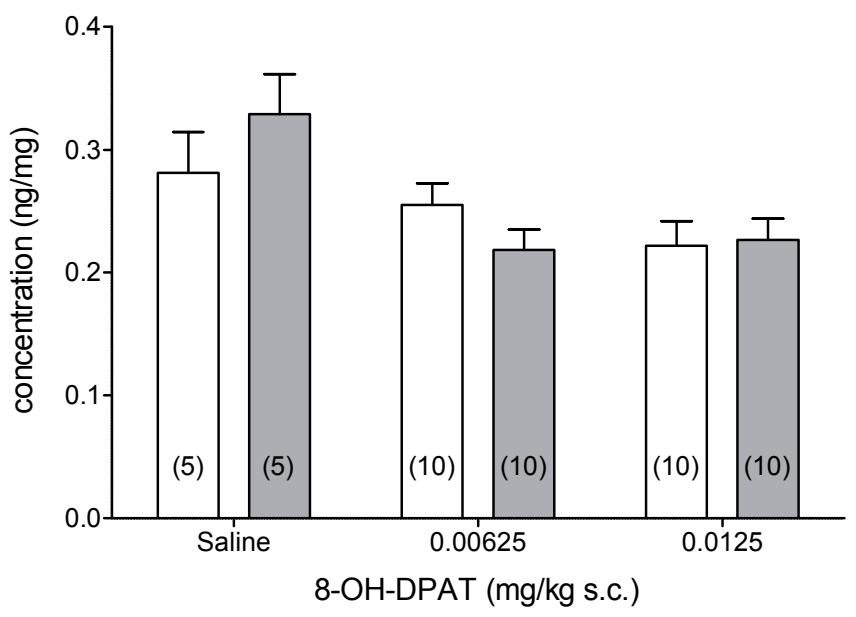

(c) hippocampus 5-HTP

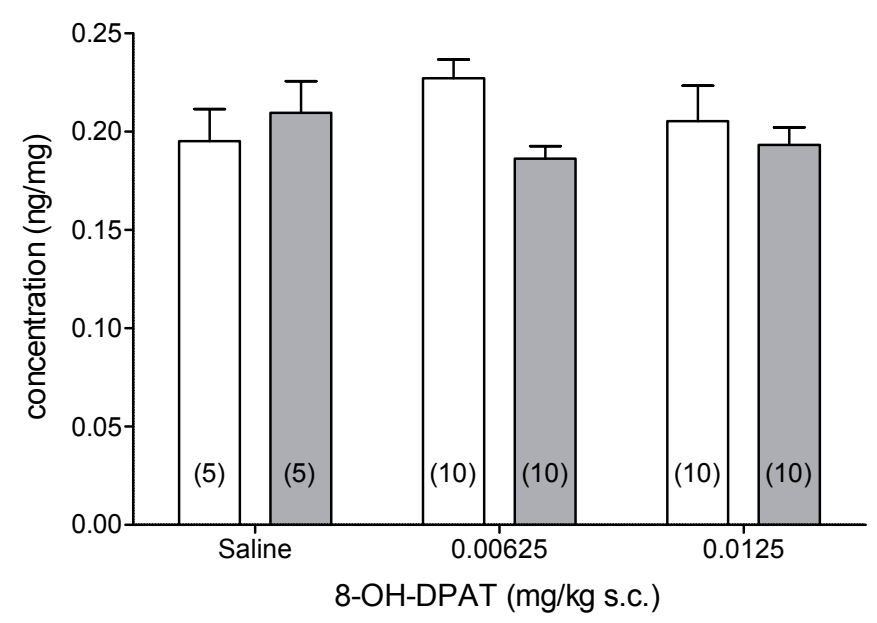

Fig. 6. 5-HTP accumulation in the frontal cortex (a), striatum (b) and hippocampus (c) in rats two weeks following pretreatment with MDMA (4x 10 $\mathrm{mg} / \mathrm{kg}$ i.p.) or saline. To measure 5-HTP accumulation, 8-OH-DPAT (0, 0.0625, or 
$0.0125 \mathrm{mg} / \mathrm{kg} \mathrm{s.c.)}$ was administered, followed 30 minutes later by NSD-1015 (100 $\mathrm{mg} / \mathrm{kg}$ i.p.), and then brains were extracted 30 minutes after NSD-1015. Mean values are plotted and error bars represent the SEM.

Experiment $2 \mathrm{~b}$ included a group that did not receive NSD-1015 to determine if the 5-HT deficit is being induced by MDMA in the rats. Figure 7 shows the results of this analysis for control rats that did not receive 8-OH-DPAT. No significant differences in 5-HT or 5-HIAA tissue levels were found between Saline and MDMA pretreated rats using t tests.

(a) frontal cortex $5-\mathrm{HT}$

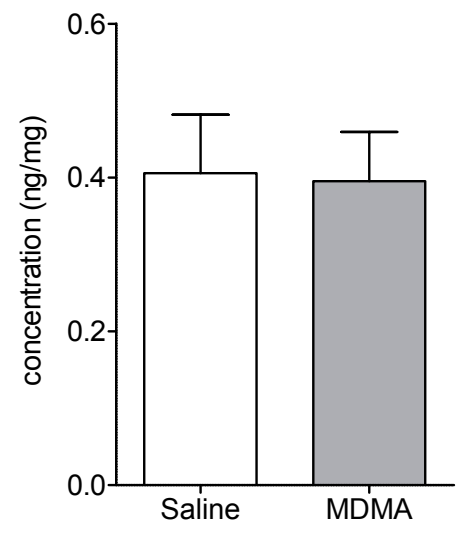

(d) frontal cortex 5-HIAA

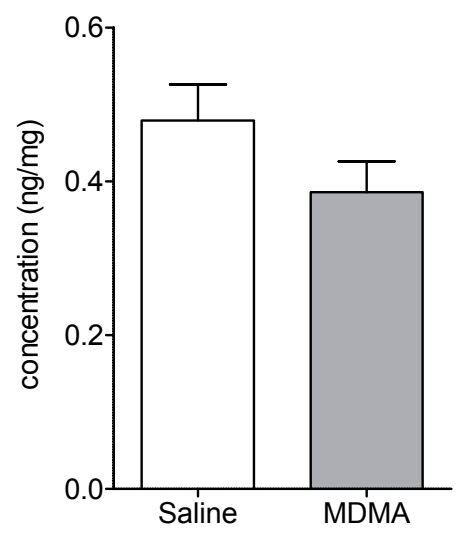

(b) striatum 5-HT

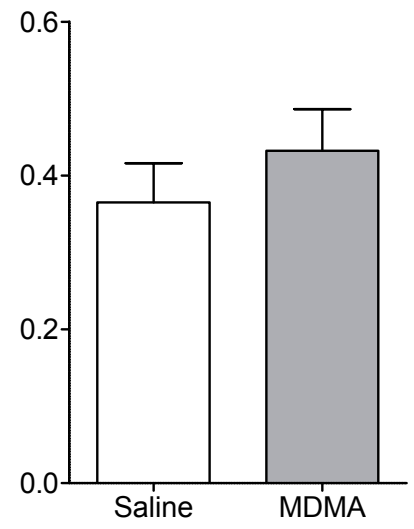

(e) striatum 5-HIAA

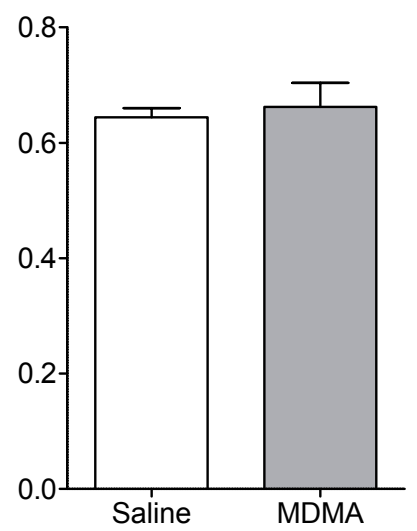

(c) hippocampus 5-HT

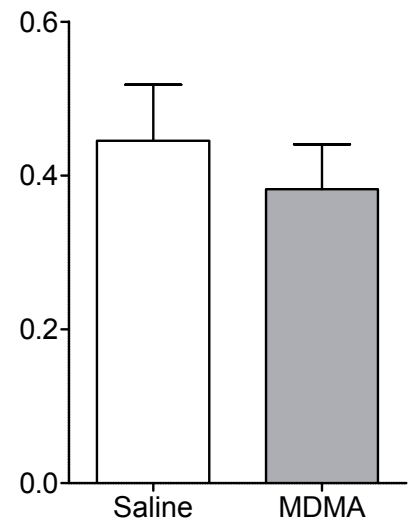

(f) hippocampus 5-HIAA

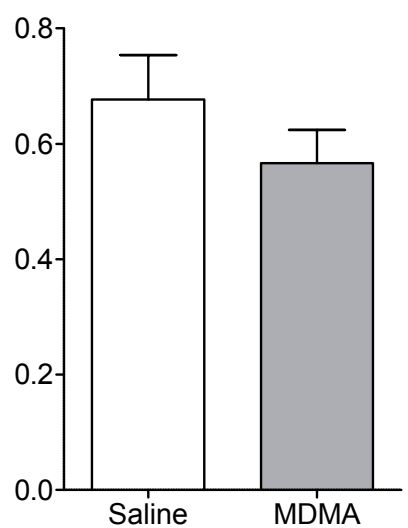

Fig. 7. 5-HT tissue levels for the frontal cortex (a), striatum (b) and hippocampus (c) of rats that received either Saline or MDMA $(4 \times 10 \mathrm{mg} / \mathrm{kg}$ i.p. $)$ pretreatment, 
without 8-OH-DPAT or NSD-1015 administration. 5-HIAA levels for the frontal cortex (d), striatum (e), hippocampus (f) for the same groups. Mean values are plotted and error bars represent the SEM. For all groups, $n=5$.

Figure 8 shows the change in core body temperature values for MDMA and saline pretreated rats as a result of 8-OH-DPAT treatment. A two-way ANOVA revealed no significant effects.

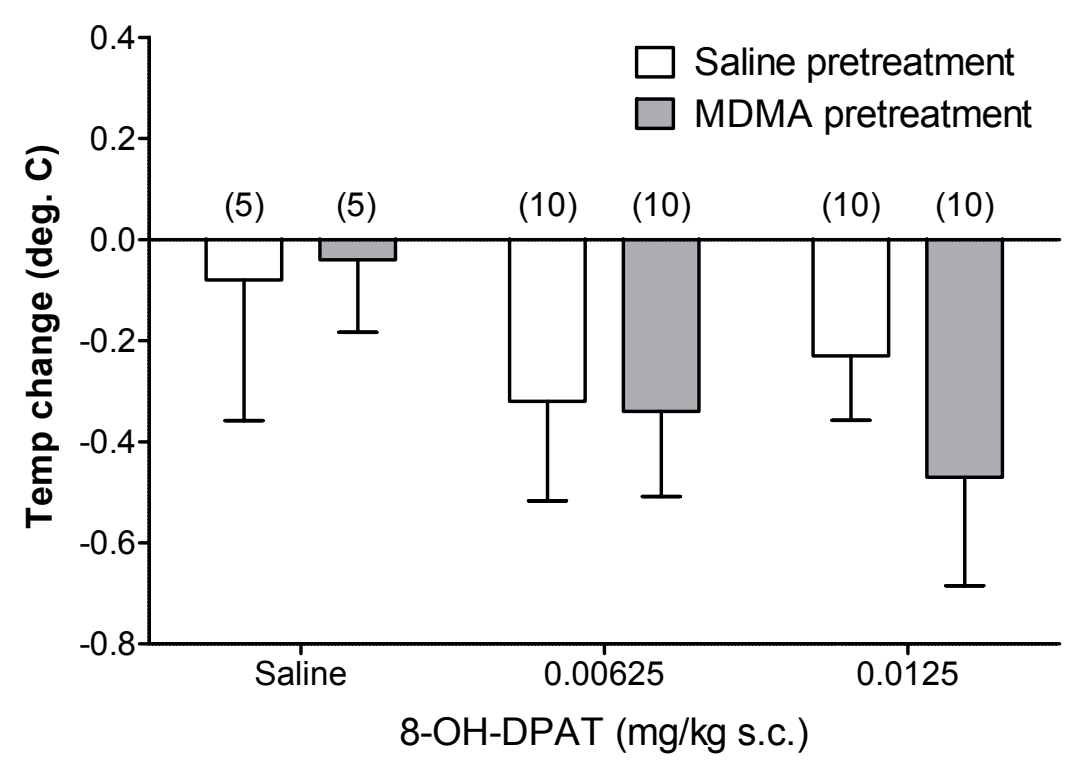

Fig. 8. Change in rectal core body temperature as a result of 8-OH-DPAT treatment for both MDMA (4x $10 \mathrm{mg} / \mathrm{kg}$ i.p.) and saline pretreated rats. Temperature measurements were assessed by rectal probe immediately prior to 8OH-DPAT injection s.c. and 30 minutes post injection. Mean values are plotted and error bars represent the SEM.

The 5-HT tissue level results presented in Experiment 2 and 3 above do not show a clear effect of MDMA pretreatment in terms of 5-HT deficits. To investigate a possible source of variability in the results, and to determine if there is a relationship between rat weight and MDMA-induced deficits, correlations 
between rat weight at the time of pretreatment and later neurochemical results were performed.

Figure 9 shows relationships between rat weight at pretreatment day and 5HT tissue concentrations two weeks later on processing day for control rats that received MDMA pretreatment and no 8-OH-DPAT or NSD-1015. It is important to remove the confounding factors of 8-OH-DPAT and NSD-1015 due to their effects on the 5-HT system. The frontal cortex (a), striatum (b) and hippocampus (c) are shown. 
(a) frontal cortex

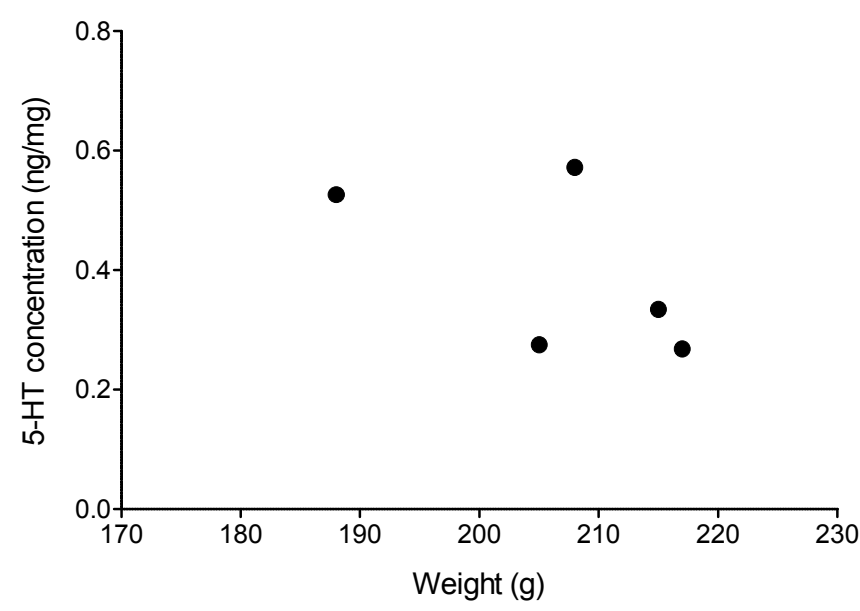

(b) striatum

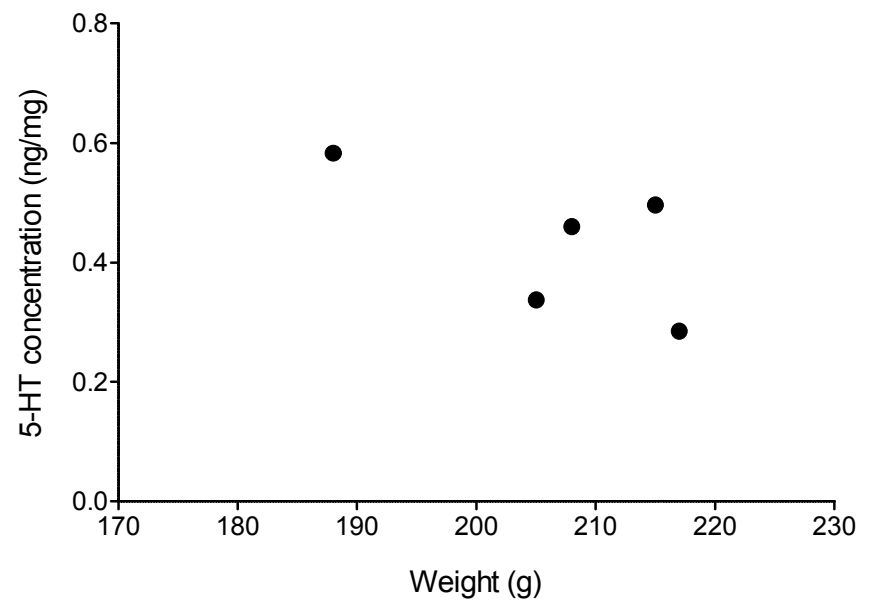

(c) hippocampus

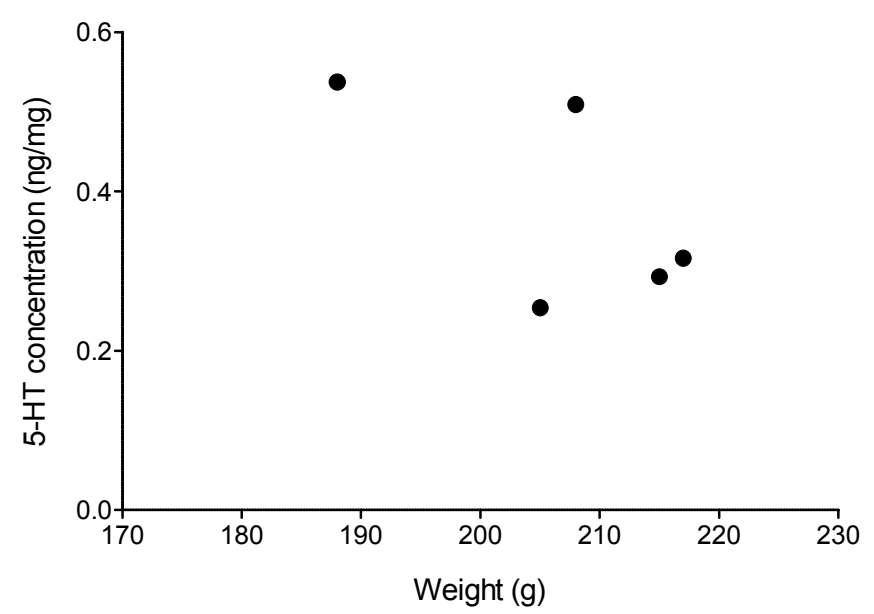

Fig. 9. Relationship between 5-HT tissue levels and pretreatment weight, in the frontal cortex (a), striatum (b) and hippocampus (c) for rats in the MDMA 
pretreatment (4x $10 \mathrm{mg} / \mathrm{kg}$ i.p.), no 8-OH-DPAT, no NSD-1015 control group. $n=$ 5.

Pearson's $\mathrm{r}$ analysis reveals moderately strong negative correlations in all three regions, $r=-.58,-.65$ and -.65 for the frontal cortex, striatum and hippocampus respectively. However, with only five values the results are not statistically significant, $p>.5$ in all cases. Hence there is a trend that lighter rats have higher 5-HT tissue levels than heavier rats. 


\section{Discussion}

The current experiments were performed to test the hypothesis that highdose, repeated MDMA treatment causes an increase in sensitivity of the $5-\mathrm{HT}_{1 \mathrm{~A}}$ autoreceptor. Unexpectedly, the results of the primary experiment indicated that MDMA pretreatment did not cause increased sensitivity of the $5-\mathrm{HT}_{1 \mathrm{~A}}$ autoreceptor, as determined by the two measures of sensitivity. No significant differences in 5-HTP tissue levels between saline and MDMA pretreated rats, at all doses of 8-OH-DPAT, were found two weeks following pretreatment. Additionally, the hypothermic response to 8-OH-DPAT was not sensitised in MDMA pretreated rats in comparison to controls, thereby also not providing evidence of increased $5-\mathrm{HT}_{1 \mathrm{~A}}$ sensitivity.

The additional investigation of lower 8-OH-DPAT doses also did not find evidence of an increase in 5- $\mathrm{HT}_{1 \mathrm{~A}}$ sensitivity. The lower doses of 8-OH-DPAT did not induce less 5-HTP accumulation in the MDMA pretreated rats, and no significant difference in hypothermic response was found between MDMA and saline groups. Therefore, the results of both experiments in the current study do not support the hypothesis that high-dose, repeated MDMA treatment increases the sensitivity of the $5-\mathrm{HT}_{1 \mathrm{~A}}$ autoreceptor.

To investigate why no significant changes in 5-HTP accumulation or hypothermic effect were found, the first area of interest is the validity of the procedure in measuring the variables under examination. NSD-1015 acted as expected in inhibiting the conversion of 5-HTP to 5-HT and dramatically increasing 5-HTP levels. Additionally, 8-OH-DPAT was found to produce the expected result in decreasing accumulated 5-HTP levels, presumably via activation of 5-HT ${ }_{1 \mathrm{~A}}$ autoreceptors (Hjorth et al., 1982; Hjorth, 1985; Hillegaart, 1991). Hence the methodology appears sound in these regards, although possible reasons for not finding MDMA-induced changes in 5-HTP accumulation or 5$\mathrm{HT}_{1 \mathrm{~A}}$ hypothermia can be investigated further. 


\section{5-HT Deficits}

One important factor that could explain why there are no sensitivity changes due to MDMA is that there is weak evidence in the current experiments of the expected MDMA-induced 5-HT deficits in control rats that did not receive 8-OHDPAT. Only in the hippocampus (Figure 4c) was there a significant difference in 5-HT levels between saline and MDMA groups, with the MDMA pretreatment group at $77 \%$ of control. A substantial reduction in 5-HT and 5-HIAA tissue levels would be expected given the results of other studies that have found such 5HT deficits in the frontal cortex, striatum and hippocampus two weeks following MDMA doses of 4x $10 \mathrm{mg} / \mathrm{kg}$ i.p. For example, with this dosing regime Scanzello et al. (1993) reported 5-HT levels in MDMA pretreated rats as 22\% of control in the frontal cortex, $58 \%$ of control in the striatum and $34 \%$ of control in the hippocampus. Additionally, with the same MDMA regime Fischer et al. (1995) reported similar reductions in 5-HIAA tissue levels, to $35 \%$ of control in the frontal cortex, $40 \%$ of control in the striatum and $32 \%$ of control in the hippocampus. The lack of 5-HT deficits in the current study is a critical issue, as it does not allow the original hypothesis that MDMA supersensitises the 5- $\mathrm{HT}_{1 \mathrm{~A}}$ autoreceptor to be properly addressed. While it may be possible that MDMAinduced changes in 5-HT $\mathrm{HA}_{1 \mathrm{~A}}$ autoreceptor sensitivity could occur without conventional 5-HT deficits, without evidence of these 5-HT deficits there is less basis on which to expect changes in the autoreceptor.

A potential reason for the unsubstantial evidence of MDMA-induced 5-HT deficits was the effect of NSD-1015 on the serotonin system, presented in Figure 1. The drug acted to significantly increase 5 -HT levels by $27 \%$, decrease 5 -HIAA levels by $37 \%$, and decrease 5 -HT turnover by $49 \%$. A possible explanation of these results is that compensatory mechanisms act to maintain 5-HT levels by reducing catabolism of the neurotransmitter as a result of having a severely inhibited tryptophan enzyme. Therefore, the effects of NSD-1015 could have overshadowed the expected 5-HT deficits produced by MDMA. To test this, a group that did not receive NSD-1015 was analysed to determine if the MDMAinduced 5-HT deficits were present (Figure 7). No significant difference in 5-HT or 5-HIAA levels between saline and MDMA pretreated rats was also found in 
these groups that did not receive NSD-1015. Therefore, the NSD-1015 treatment is not impacting on the 5-HT deficits that should be produced by MDMA. The lack of substantial 5-HT deficits casts doubt on the efficacy of the MDMA pretreatment regime to produce deficits in the particular sample of rats used in the current experiments. To investigate this further it is worth examining the characteristics of these rats.

\section{Rat Characteristics}

There are a number of possible reasons why there was no strong evidence of MDMA-induced 5-HT deficits in the rats used. It is known that the extent of MDMA-induced serotonergic deficits in rats is determined by dose, dosing regime, rat strain, body temperature and age (Broening, Bowyer, \& Slikker, 1995; O'Shea, Granados, Esteban, Colado, \& Green, 1998; Green, Mechan, Elliott, O’Shea, \& Colado, 2003). Previous research, as described earlier, has shown significant 5HT deficits in rats with the same dose, dosing regime and strain as used in the current experiments. However, much of this research uses larger adult rats that are more susceptible to MDMA-induced 5-HT deficits. For example, Scanzello et al. (1993) reported significant 5-HT deficits with Sprague-Dawley rats at PD 77, weighing approximately $350 \mathrm{~g}$. The weight, and hence age, of the rats used in the current experiments is a potential reason for the lack of 5-HT deficits.

The rats used in the current experiments had a mean weight of $198 \mathrm{~g}$, with a range between $172 \mathrm{~g}$ and $226 \mathrm{~g}$. The ages of the rats in post natal days (PD) are unknown, although they can be estimated from a Sprague-Dawley weight chart (Harlan Labs, 2009), giving a range of approximately PD 42 to PD 50, with a mean of PD 46. This age range puts the rats in their adolescence, a neurodevelopmental stage characterised in all species by extensive change, with the serotonergic system undergoing substantial reorganisation (Spear, 2000). For instance, Chen, Turiak, Galler and Volicer (1997) reported that hippocampal 5HT levels in rats at PD 45 were six times higher than at juvenile and adult ages. Furthermore, Broening, Bacon and Slikker (1994) showed that MDMA has varying effects on individual neurochemical components at different developmental stages. Due to these factors, MDMA has more variable effects in adolescent rats and 5-HT deficits, if they develop at all, are more transient. 
It has been reported that rats up to PD 35-40 do not exhibit MDMAinduced 5-HT deficits following 10-40 mg/kg MDMA, as evidenced by there being no significant decrease in 5-HT transporter density or 5-HT levels (Broening et al., 1994). The researchers showed that PD 40 is the approximate age at which susceptibility to 5-HT deficits begins. Fone et al. (2002) demonstrated that even this might be conservative, as they reported no 5-HT deficits in PD 40 rats 12 days following a MDMA dosing regime of $45 \mathrm{mg} / \mathrm{kg}$ over a period of 3 days. Therefore the majority of the rats used in this study were close to the age at which MDMA-induced 5-HT deficits begin to manifest, and therefore had a considerably low likelihood of developing lasting 5-HT deficits. This is reflected in the current results in Figure 9, which shows a trend for rats that were younger when administered MDMA to have higher 5-HT tissue levels two weeks later than rats that were older. This trend can be interpreted to mean that younger rats are less susceptible to the 5-HT deficits induced by MDMA pretreatment than are older rats.

Further studies also reveal the difficulties in assessing 5-HT deficits in adolescent rats. Piper and Meyer (2004) found no significant long-term differences in SERT binding in Sprague-Dawley rats that received six $20 \mathrm{mg} / \mathrm{kg}$ MDMA injections between PD 35 and PD 60. This is a similar age distribution to the rats in the present study, although the dosing regime is considerably different. In addition, Marston et al. (1999) reported moderate significant 5-HT deficits in rats weighing 150-180g, 16 days following a MDMA regime of $90 \mathrm{mg} / \mathrm{kg}$ in total over three days. While this study is not directly comparable to the current experiments due to the considerable differences in MDMA dose and the use of Lister Hooded rats, it may imply that a significant deficit would have been seen in the current study with a considerably higher MDMA dose. It is also possible that 5-HT deficits would have been evident in the current experiments at one week post MDMA pretreatment, as opposed to two weeks. Broening, Bacon and Slikker (Broening et al., 1994) found 5-HT deficits one week after a single $40 \mathrm{mg} / \mathrm{kg}$ MDMA injection in PND 40 rats. In summary it is evident that MDMA-induced 5-HT deficits in adolescent rats are transient if detectable at all, and therefore rats of this developmental period are unlikely to exhibit 5-HT deficit-related changes in $5-\mathrm{HT}_{1 \mathrm{~A}}$ autoreceptor sensitivity. The present experiments contribute to the body 
of literature by providing further evidence of the effects of MDMA in adolescent rats.

\section{Ambient Temperature}

A further factor that may have contributed to the unsubstantial 5-HT deficits is the ambient temperature of the room in which rats were administered MDMA. A large body of findings demonstrate that the ambient temperature has a considerable impact on 5-HT deficits induced by MDMA (Schmidt, Black, Abbate, \& Taylor, 1990; Miller \& O’Callaghan, 1994; Farfel \& Seiden, 1995; Dafters, 1995; Malberg \& Seiden, 1998). The ambient temperature in the current experiments was controlled at $21^{\circ} \mathrm{C}$, which as revealed by Malberg and Seiden, is not necessarily conducive to inducing 5-HT deficits. Malberg and Seiden reported that at temperatures of $20-24^{\circ} \mathrm{C}$ there were no deficits in 5-HT and 5-HIAA levels in the frontal cortex, striatum or hippocampus two weeks following MDMA (40 $\mathrm{mg} / \mathrm{kg}$ ) administration in adult rats, with deficits only evident at temperatures above $24^{\circ} \mathrm{C}$. The importance of ambient temperature is also seen in that some researchers use an increased temperature to encourage MDMA-induced deficits (2001). Conversely, there are reports of substantial MDMA-induced 5-HT deficits at ambient temperatures of approximately $22^{\circ} \mathrm{C}$ (Scanzello et al., 1993; Fischer et al., 1995). In summary, the evidence suggests that at between 20 and $24^{\circ} \mathrm{C} 5$-HT deficits are more elusive than at higher temperatures. Therefore, the ambient temperature in the current experiments could have had a marked impact in preventing 5-HT deficits.

\section{Hypothermic Response}

Previous studies that have examined the influence of repeated MDMA exposure on the hypothermic response to 8-OH-DPAT found either no change (McNamara, Kelly, \& Leonard, 1995; Granoff \& Ashby, 2001; Mechan, O’Shea, Elliott, Colado, \& Green, 2001) or a potentiation of the response (Aguirre et al., 1998). The 8-OH-DPAT hypothermic response results in the current experiments are consistent with those that found no change. Potentiation of the hypothermic response, as found by Aguirre et al., would have been the expected result 
consistent with the hypothesis of this study. However, there are a number of factors that make the 8-OH-DPAT hypothermic response difficult to use as a measure of $5-\mathrm{HT}_{1 \mathrm{~A}}$ sensitivity. First, the exact method of action of the hypothermic response to 8-OH-DPAT remains a controversial issue. For instance, Aguirre et al. attributed the potentiation they found to changes in the postsynaptic 5- $\mathrm{HT}_{1 \mathrm{~A}}$ heteroreceptors, as they took the position that 8-OH-DPAT's hypothermic response is postsynaptically mediated. Second, with systemic administration of 8OH-DPAT it is not possible to know the degree to which the drug is activating pre or postsynaptic 5- $\mathrm{HT}_{1 \mathrm{~A}}$ receptors and hence where the neuroadaptations occur. For instance, Aguirre et al. used a larger $1 \mathrm{mg} / \mathrm{kg}$ dose in comparison to the smaller, autoreceptor-selective doses used in the current experiments, and therefore potentially activated postsynaptic heteroreceptors. Third, 8-OH-DPAT has significant agonist activity at 5-HT7 receptors in addition to 5- $\mathrm{HT}_{1 \mathrm{~A}}$ receptors, and 5-HT7 receptors may be the most important for eliciting hypothermia within the dose range of 8-OH-DPAT used in the present study (Hedlund et al., 2004). Thus, the hypothermic effect of 8-OH-DPAT is complex and is likely to involve multiple receptor subtypes, which introduces confounding factors when attempting to selectively measure changes in $5-\mathrm{HT}_{1 \mathrm{~A}}$ autoreceptor sensitivity.

\section{Methodological Issues and Stress}

Several further methodological issues in the current experiments are worth discussing. The hypothermic response measurement was performed using a rectal probe, which presents a number of challenges. The rats must be handled, sometimes at length, for accurate measurements to be recorded. This procedure can be highly stressful to the animal, and the associated synthesis-dependent increases in 5-HT levels caused by the stress response introduce more variability into the data (Joseph \& Kennett, 1983; Adell, Casanovas, \& Artigas, 1997). Another high stress procedure was administration of NSD-1015. Due to the concentration required of the drug it was mixed at $20 \mathrm{mg} / \mathrm{ml}$ and hence required a large volume of fluid to be injected, which took markedly longer than a typical i.p. injection. Furthermore, the solution often caused an adverse reaction in the rats for unknown reasons. Adell et al. reported that a subcutaneous injection of saline $(1 \mathrm{mg} / \mathrm{ml})$ caused 5 -HT increases of up to $220 \%$ of baseline in the raphe nuclei, 
and $160 \%$ of baseline in the amygdala, peaking at 30 minutes. Related to this, Joseph and Kennett revealed that such stress-induced 5-HT release is dependent on an increase in 5-HT synthesis, and hence should affect tissue level measurements. Therefore, it was likely that the handling required for temperature measurements and the additional stress response of the NSD-1015 administration introduced a considerable degree of variability in the 5-HT measurements.

\section{Alternative Hypotheses}

Irrespective of the lack of 5-HT deficits, the possibility exists that the 5$\mathrm{HT}_{1 \mathrm{~A}}$ autoreceptor does not become supersensitised following MDMA pretreatment, and hence no significant variation in 8-OH-DPAT effect would be expected in MDMA pretreated rats. MDMA-induced impairments could result from neuroadaptations to another component of the 5-HT system. For instance, changes in sensitivity of the postsynaptic $5-\mathrm{HT}_{1 \mathrm{~A}}$ heteroreceptor may contribute to MDMA-induced impairments. The 5- $\mathrm{HT}_{1 \mathrm{~A}}$ heteroreceptors regulate, usually negatively, the activity of non-serotonergic neurons in 5-HT terminal areas by coupling to inhibitory $\mathrm{G}$ proteins $(\mathrm{Gi} / \mathrm{o})$ and inhibiting adenylate cyclase (De Vivo \& Maayani, 1986; Sprouse \& Aghajanian, 1988). As a consequence, changes in 5$\mathrm{HT}_{1 \mathrm{~A}}$ heteroreceptors can cause lasting changes in protein expression and cellular activity. Furthermore, while 5- $\mathrm{HT}_{1 \mathrm{~A}}$ autoreceptors primarily control serotonergic neuronal firing, 5- $\mathrm{HT}_{1 \mathrm{~A}}$ heteroreceptors may also play a role in the regulation of

firing rate and serotonin release of 5-HT neurons through neuronal feedback loops between projection areas and raphe nuclei (Ceci, Baschirotto, \& Borsini, 1994; Bosker, Klompmakers, \& Westenberg, 1997; Hajós, Hajós-Korcsok, \& Sharp, 1999; Celada, Puig, Casanovas, Guillazo, \& Artigas, 2001). In this way, it is possible that neuroadaptations in postsynaptic $5-\mathrm{HT}_{1 \mathrm{~A}}$ heteroreceptors could have a direct impact on 5-HT transmission, and hence be a potential cause of 5-HTrelated impairments induced by MDMA. Evidence for this argument comes from a study in which repeated MDMA exposure caused an increase in 5-HT $\mathrm{HA}_{1 \mathrm{~A}}$ heteroreceptor binding in the frontal cortex 7 days later (Aguirre, Galbete, Lasheras, \& Del Río, 1995). The authors note that this change would make sense in terms of adaptive changes to compensate for reduced functioning of the 5-HT system. 


\section{5-HT $T_{1 A}$ Desensitisation}

A further alternative hypothesis is that MDMA impairments stem from a desensitisation of the 5- $\mathrm{HT}_{1 \mathrm{~A}}$ autoreceptor, as opposed to a supersensitisation. Aguirre, Galbete, Lasheras and Del Rio (1995) also reported a reduction in 5$\mathrm{HT}_{1 \mathrm{~A}}$ binding in the brain stem area incorporating the raphe nuclei, and argued that this MDMA-induced desensitisation of 5- $\mathrm{HT}_{1 \mathrm{~A}}$ autoreceptors may be due to a compensatory mechanism in response to the putative loss of 5-HT nerve terminals. In the current experiments, possible evidence of desensitisation of the 5- $\mathrm{HT}_{1 \mathrm{~A}}$ autoreceptor is seen in Figure 5, which shows that there was a nonsignificant trend in the MDMA pretreated rats of an attenuated 8-OH-DPAT hypothermic response. This is consistent with the argument of Aguirre et al. (1998) that MDMA induces down-regulation of presynaptic 5- $\mathrm{HT}_{1 \mathrm{~A}}$ autoreceptors. However, as previously discussed, the hypothermic response measurement is problematic.

Desensitisation of the 5- $\mathrm{HT}_{1 \mathrm{~A}}$ autoreceptor may be an expected response to MDMA for a number of reasons. MDMA functions in part by dramatically increasing available 5-HT that, in the raphe nuclei, acts as an agonist to $5-\mathrm{HT}_{1 \mathrm{~A}}$ autoreceptors. In this sense, MDMA indirectly acts like the 5- $\mathrm{HT}_{1 \mathrm{~A}}$ agonist 8-OHDPAT, which has been shown to cause internalisation of 5- $\mathrm{HT}_{1 \mathrm{~A}}$ autoreceptors in the DRN 15 minutes after systemic administration $(0.5 \mathrm{mg} / \mathrm{kg}$ i.v.) (Riad, Watkins, Doucet, Hamon, \& Descarries, 2001). It is also established that long term activation of the 5- $\mathrm{HT}_{1 \mathrm{~A}}$ autoreceptor leads to desensitisation through an internalisation of the receptor (Kreiss \& Lucki, 1997; Dong, De Montigny, \& Blier, 1997; Blier, Pineyro, El Mansari, Bergeron, \& De Montigny, 1998; Blier \& De Montigny, 1998; Riad et al., 2000; Assié, Lomenech, Ravailhe, Faucillon, \& Newman-Tancredi, 2006). Moreover, selective serotonin reuptake inhibitors (SSRIs), which act in part similar to MDMA in terms of increasing available 5HT, eventually cause desensitisation of $5-\mathrm{HT}_{1 \mathrm{~A}}$ autoreceptors (Blier \& De Montigny, 1998; Le Poul et al., 2000). Additionally, reductions in the SERT protein in the raphe nuclei via gene transfer have been shown to cause a desensitisation of 5- $\mathrm{HT}_{1 \mathrm{~A}}$ receptors, as determined by a decrease in $5-\mathrm{HT}_{1 \mathrm{~A}}$ receptor-stimulated $\left[{ }^{35} \mathrm{~S}\right] \mathrm{GTP}-\gamma-\mathrm{S}$ binding (Fabre et al., 2000). MDMA also causes reductions in SERT expression (Battaglia et al., 1988; Scanzello et al., 1993; O'Shea et al., 2006). With respect to these points, it would make sense for 
MDMA to cause a desensitisation of the 5- $\mathrm{HT}_{1 \mathrm{~A}}$ autoreceptor, as opposed to the hypothesised supersensitisation.

An important consideration with the desensitisation hypothesis is that a desensitised 5- $\mathrm{HT}_{1 \mathrm{~A}}$ autoreceptor does not align well with the cognitive and mood impairments associated with MDMA abuse. Desensitisation of the autoreceptor would enhance serotonergic neurotransmission - an outcome typically associated with wellbeing and an important method of action of SSRIs. Moreover, MDMA has many effects in addition to causing 5-HT release and potentially desensitising autoreceptors, and hence cannot be characterised solely in this way. In fact, the 5HT deficits caused by MDMA are likely to be due to other factors beyond the dramatic increase in 5-HT (Baumann, Ayestas, Dersch, \& Rothman, 2001). Therefore, while there is a case for desensitisation of $5-\mathrm{HT}_{1 \mathrm{~A}}$ autoreceptors with respect to one aspect of MDMA pharmacodynamics, it is unlikely to be at the root of 5-HT deficits induced by MDMA. Additionally, although it is possible that 5$\mathrm{HT}_{1 \mathrm{~A}}$ autoreceptor desensitisation and 5-HT deficits could occur independently, it would seem unlikely that such an instrumental regulatory component of the 5-HT system is not involved in the deficits and consequent functional impairments of MDMA abuse.

\section{Future Research}

There is a large degree of equivocacy in the MDMA studies investigating 5$\mathrm{HT}_{1 \mathrm{~A}}$ functioning, which is also reflected in studies that consider $5-\mathrm{HT}_{1 \mathrm{~A}}$ functioning with other psychostimulants. For instance, with respect to binding studies, experiments with the effects of other psychostimulants on 5-HT $\mathrm{HA}_{1 \mathrm{~A}}$ binding report a complex mix of up and down receptor regulation, which are difficult to replicate and show no clear picture overall (Müller, Carey, Huston, \& De Souza Silva, 2007). For these reasons, Müller et al. suggest that the 5- $\mathrm{HT}_{1 \mathrm{~A}}$ receptor may not be a good candidate to explain long-term impairments caused by psychostimulants such as MDMA. However, the theoretical basis behind MDMAinduced sensitivity changes in the $5-\mathrm{HT}_{1 \mathrm{~A}}$ autoreceptor is sound and it is too early to draw any reliable conclusions until the shortcomings of the present experiments are overcome by future research. Furthermore, even if an increase in autoreceptor sensitivity is not ultimately the central explanatory factor, there is considerable 
theoretical support and evidence for other neuroadaptive changes in the $5-\mathrm{HT}_{1 \mathrm{~A}}$ receptor system that are likely to provide a source of valuable future research.

There are a number of possibilities for future research to overcome the shortcomings of the current experiments. First, adult rats with a more tightly restricted weight range should be used. It is evident that long-term MDMAinduced 5-HT deficits are highly variable or non-existent in adolescent rats, potentially due to their still developing 5-HT system. The use of adult rats would ensure more marked and consistent 5-HT deficits and hence allow the investigation of sensitivity changes in the $5-\mathrm{HT}_{1 \mathrm{~A}}$ autoreceptor that may form part of these deficits. Second, the ambient temperature during MDMA administration should be maintained at a higher temperature, at least over $24^{\circ} \mathrm{C}$, to ensure significant 5-HT deficits. Moreover, a higher ambient temperature above $21^{\circ} \mathrm{C}$ is closer to temperatures experienced by human MDMA users in a typical club environment (Schifano, 2004) and hence provides more ecological validity. Third, higher doses of MDMA, or a dosing regime that extends over multiple days, could be used to produce more marked 5-HT deficits. More profound deficits may be required to see changes in 5- $\mathrm{HT}_{1 \mathrm{~A}}$ autoreceptors. Fourth, the use of other behavioural methods for investigating $5-\mathrm{HT}_{1 \mathrm{~A}}$ autoreceptor state may assist in detecting sensitivity changes. For example, lower lip retraction is a behavioural measure of 5- $\mathrm{HT}_{1 \mathrm{~A}}$ autoreceptor activation (Berendsen, Jenck, \& Broekkamp, 1989; Moore, Rees, Sanger, \& Perrett, 1993) and hence could be used as a correlate measure for changes in receptor sensitivity.

With respect to the aforementioned points, the first step in the future would be to repeat Experiment 2 with adult rats, and a consistent ambient temperature of $25^{\circ} \mathrm{C}$ during MDMA administration. This should produce reliable 5-HT deficits and consequently allow valid investigation of changes in $5-\mathrm{HT}_{1 \mathrm{~A}}$ autoreceptor sensitivity. The addition of an alternative behavioural measure of 5- $\mathrm{HT}_{1 \mathrm{~A}}$ sensitivity, such as lower lip retraction, would provide greater evidence that the 5$\mathrm{HT}_{1 \mathrm{~A}}$ autoreceptor is implicated. If this next experiment fails to find any 5-HTP or behavioural differences in the MDMA pretreated group, then further experiments could be performed with higher doses of MDMA over multiple days. If either of these experiments are successful at finding changes in 5-HTP accumulation or 
behavioural measures that would imply sensitivity changes of $5-\mathrm{HT}_{1 \mathrm{~A}}$ autoreceptors, then the next step would be to more firmly establish these findings through binding studies, electrophysiological methods and more valid animal models of substance abuse and addiction.

Ultimately, to show changes in sensitivity, a number of further studies would be required. Binding measurements of 5- $\mathrm{HT}_{1 \mathrm{~A}}$ agonists in the raphe nuclei at multiple time points after repeated MDMA exposure may provide further evidence of sensitivity changes. Additionally, histological analysis of receptors to investigate their location in the cell post MDMA exposure could provide evidence of the mechanisms of sensitivity changes, such as if receptor internalisation occurs. Finally, using in vivo electrophysiological methods it would be possible to examine the responses of individual 5-HT neurons in the rat raphe nuclei to 5$\mathrm{HT}_{1 \mathrm{~A}}$ receptor activation following MDMA pretreatment, to determine directly changes in sensitivity via firing rate properties.

A further important future step in the research of 5- $\mathrm{HT}_{1 \mathrm{~A}}$ functioning and involvement in MDMA-induced impairments is using animals that have established addiction-related behaviour, such as those self-administering MDMA. The self-administration paradigm is a far superior approximation of human drug taking behaviour, and hence of the resulting deficits. While MDMA selfadministration has been well established (Schenk, Gittings, Johnstone, \& Daniela, 2003; Schenk et al., 2007; Schenk, 2009), at present there are no studies available that have measured 5- $\mathrm{HT}_{1 \mathrm{~A}}$ sensitivity changes due to prolonged MDMA exposure in a self-administration paradigm.

\section{Summary}

The current experiments did not find evidence to support the hypothesis that high-dose, repeated MDMA exposure leads to an increase in sensitisation of the $5-\mathrm{HT}_{1 \mathrm{~A}}$ autoreceptor. This was shown through an inability of autoreceptorselective doses of 8-OH-DPAT to produce sensitised 5-HTP accumulation and a sensitised hypothermic response. Therefore, the results of the current experiments would suggest that 5- $\mathrm{HT}_{1 \mathrm{~A}}$ supersensitisation does not result from MDMA abuse and hence is not a cause of the related cognitive and mood impairments. However, 
there were a number of critical methodological issues with the current experiments, the most important being the age of the rats tested. The use of rats in their adolescence, potentially coupled with other factors such as a relatively low ambient temperature, was highly likely to prevent the formation of MDMAinduced 5-HT deficits. As these deficits are indicative of a compromised 5-HT system, without their presence there is little basis on which to investigate neuroadaptations in the $5-\mathrm{HT}_{1 \mathrm{~A}}$ autoreceptor.

The current experiments contribute additional evidence of the nature of MDMA-induced 5-HT deficits in adolescent rats, and also further insight into the mechanisms of action of NSD-1015 and 8-OH-DPAT in the 5-HT system of adolescent rats. It is hoped that future research will overcome the shortcomings of the current experiments and contribute further valuable findings to the body of MDMA knowledge. 


\section{References}

Adell, A., Carceller, A., \& Artigas, F. (1993). In vivo brain dialysis study of the somatodendritic release of serotonin in the Raphe nuclei of the rat: effects of 8hydroxy-2-(di-n-propylamino)tetralin. J Neurochem, 60(5), 1673-1681.

Adell, A., Casanovas, J. M., \& Artigas, F. (1997). Comparative study in the rat of the actions of different types of stress on the release of 5-HT in raphe nuclei and forebrain areas. Neuropharmacology, 36(4-5), 735-741.

Aguirre, N., Ballaz, S., Lasheras, B., \& Del Río, J. (1998). MDMA ('Ecstasy') enhances 5-HT1A receptor density and 8-OH-DPAT-induced hypothermia: blockade by drugs preventing 5-hydroxytryptamine depletion. Eur J Pharmacol, 346(2-3), 181-188.

Aguirre, N., Frechilla, D., García-Osta, A., Lasheras, B., \& Del Río, J. (1997).

Differential regulation by methylenedioxymethamphetamine of 5hydroxytryptamine1A receptor density and mRNA expression in rat hippocampus, frontal cortex, and brainstem: the role of corticosteroids. $J$ Neurochem, 68(3), 1099-1105.

Aguirre, N., Galbete, J. L., Lasheras, B., \& Del Río, J. (1995).

Methylenedioxymethamphetamine induces opposite changes in central pre- and postsynaptic 5-HT1A receptors in rats. Eur J Pharmacol, 281(1), 101-105.

Albert, P. R., Lembo, P., Storring, J. M., Charest, A., \& Saucier, C. (1996). The 5HT1A receptor: signaling, desensitization, and gene transcription. Neuropsychopharmacology, 14(1), 19-25.

Albert, P. R., Zhou, Q. Y., Van Tol, H. H., Bunzow, J. R., \& Civelli, O. (1990). Cloning, functional expression, and mRNA tissue distribution of the rat 5hydroxytryptamine1 A receptor gene. J Biol Chem, 265(10), 5825-5832.

Altman, H. J., Nordy, D. A., \& Ogren, S. O. (1984). Role of serotonin in memory: facilitation by alaproclate and zimeldine. Psychopharmacology, 84(4), 496-502.

Andrade, R., Malenka, R. C., \& Nicoll, R. A. (1986). A G protein couples serotonin and GABAB receptors to the same channels in hippocampus. Science (New York, NY), 234(4781), 1261-1265.

Andrade, R., \& Nicoll, R. A. (1987). Pharmacologically distinct actions of serotonin on single pyramidal neurones of the rat hippocampus recorded in vitro. $J$ Physiol (Lond), 394, 99-124.

Assié, M., Lomenech, H., Ravailhe, V., Faucillon, V., \& Newman-Tancredi, A. (2006). Rapid desensitization of somatodendritic 5-HT1A receptors by chronic administration of the high-efficacy 5-HT1A agonist, F13714: a microdialysis study in the rat. British Journal of Pharmacology, 149(2), 170-178.

Azmitia, E. C., \& Segal, M. (1978). An autoradiographic analysis of the differential ascending projections of the dorsal and median raphe nuclei in the rat. J Comp Neurol, 179(3), 641-667. 
Bai, F., Jones, D. C., Lau, S. S., \& Monks, T. J. (2001). Serotonergic neurotoxicity of 3,4-(+/-)-methylenedioxyamphetamine and 3,4-(+/-)methylendioxymethamphetamine (ecstasy) is potentiated by inhibition of gamma-glutamyl transpeptidase. Chem Res Toxicol, 14(7), 863-870.

Barnes, N. M., \& Sharp, T. (1999). A review of central 5-HT receptors and their function. Neuropharmacology, 38(8), 1083-1152.

Battaglia, G., Yeh, S. Y., \& De Souza, E. B. (1988). MDMA-induced neurotoxicity: parameters of degeneration and recovery of brain serotonin neurons. Pharmacol Biochem Behav, 29(2), 269-274.

Baumann, M. H., Ayestas, M. A., Dersch, C. M., \& Rothman, R. B. (2001). 1-(mchlorophenyl)piperazine ( $\mathrm{mCPP}$ ) dissociates in vivo serotonin release from long-term serotonin depletion in rat brain. Neuropsychopharmacology, 24(5), 492-501.

Baumann, M. H., Clark, R. D., Franken, F. H., Rutter, J. J., \& Rothman, R. B. (2008). Tolerance to 3,4-methylenedioxymethamphetamine in rats exposed to single high-dose binges. Neuroscience, 152(3), 773-784.

Baumann, M. H., Wang, X., \& Rothman, R. B. (2007). 3,4Methylenedioxymethamphetamine (MDMA) neurotoxicity in rats: a reappraisal of past and present findings. Psychopharmacology, 189(4), 407-424.

Benzenhöfer, U., \& Passie, T. (2006). The early history of "Ecstasy". Nervenarzt, 77(1), 95-6, 98-9.

Berendsen, H. H., Jenck, F., \& Broekkamp, C. L. (1989). Selective activation of 5HT1A receptors induces lower lip retraction in the rat. Pharmacol Biochem Behav, 33(4), 821-827.

Biezonski, D., \& Meyer, J. (2010). Effects of 3,4-methylenedioxymethamphetamine (MDMA) on serotonin transporter and vesicular monoamine transporter 2 protein and gene expression in rats: implications for MDMA neurotoxicity. Journal of Neurochemistry, 112(4), 951-962.

Bill, D. J., Knight, M., Forster, E. A., \& Fletcher, A. (1991). Direct evidence for an important species difference in the mechanism of 8-OH-DPAT-induced hypothermia. Br J Pharmacol, 103(4), 1857-1864.

Blier, P., \& De Montigny, C. (1990). Electrophysiological investigation of the adaptive response of the 5-HT system to the administration of 5-HT1A receptor agonists. J Cardiovasc Pharmacol, 15 Suppl 7, S42-8.

Blier, P., \& De Montigny, C. (1998). Possible serotonergic mechanisms underlying the antidepressant and anti-obsessive-compulsive disorder responses. Biol Psychiatry, 44(5), 313-323.

Blier, P., De Montigny, C., \& Chaput, Y. (1987). Modifications of the serotonin system by antidepressant treatments: implications for the therapeutic response in major depression. J Clin Psychopharmacol, 7(6 Suppl), 24S-35S. 
Blier, P., Pineyro, O., El Mansari, M., Bergeron, R., \& De Montigny, C. (1998). Role of somatodendritic 5-HT autoreceptors in modulating 5-HT neurotransmission. ANNALS-NEW YORK ACADEMY OF SCIENCES, 861, 204-216.

Bolla, K. I., McCann, U. D., \& Ricaurte, G. A. (1998). Memory impairment in abstinent MDMA ("Ecstasy") users. Neurology, 51(6), 1532-1537.

Bonhomme, N., Cador, M., Stinus, L., Le Moal, M., \& Spampinato, U. (1995). Short and long-term changes in dopamine and serotonin receptor binding sites in amphetamine-sensitized rats: a quantitative autoradiographic study. Brain Research, 675(1-2), 215-223.

Bonkale, W. L., \& Austin, M. C. (2008). 3,4-Methylenedioxymethamphetamine induces differential regulation of tryptophan hydroxylase 2 protein and mRNA levels in the rat dorsal raphe nucleus. Neuroscience, 155(1), 270-276.

Bonvento, G., Scatton, B., Claustre, Y., \& Rouquier, L. (1992). Effect of local injection of 8-OH-DPAT into the dorsal or median raphe nuclei on extracellular levels of serotonin in serotonergic projection areas in the rat brain. Neurosci Lett, 137(1), 101-104.

Bosker, F. J., Donker, M. G., Klompmakers, A. A., Kurata, K., \& Westenberg, H. G. (1994). 5-Hydroxytryptamine release in dorsal hippocampus of freely moving rats: modulation by pindolol. Prog Neuropsychopharmacol Biol Psychiatry, 18(4), 765-778.

Bosker, F. J., Klompmakers, A., \& Westenberg, H. G. (1997). Postsynaptic 5-HT1A receptors mediate 5-hydroxytryptamine release in the amygdala through a feedback to the caudal linear raphe. Eur J Pharmacol, 333(2-3), 147-157.

Brennan, K. A., \& Schenk, S. (2006). Initial deficit and recovery of function after MDMA preexposure in rats. Psychopharmacology, 184(2), 239-246.

Broening, H. W., Bacon, L., \& Slikker, W. (1994). Age modulates the long-term but not the acute effects of the serotonergic neurotoxicant 3,4methylenedioxymethamphetamine. J Pharmacol Exp Ther, 271(1), 285-293.

Broening, H. W., Bowyer, J. F., \& Slikker, W. (1995). Age-dependent sensitivity of rats to the long-term effects of the serotonergic neurotoxicant (+/-)-3,4methylenedioxymethamphetamine (MDMA) correlates with the magnitude of the MDMA-induced thermal response. J Pharmacol Exp Ther, 275(1), 325-333.

Buchert, R., Thomasius, R., Petersen, K., Wilke, F., Obrocki, J., Nebeling, B. et al. (2006). Reversibility of ecstasy-induced reduction in serotonin transporter availability in polydrug ecstasy users. Eur J Nucl Med Mol Imaging, 33(2), 188199.

Byrne, T., Baker, L. E., \& Poling, A. (2000). MDMA and learning: effects of acute and neurotoxic exposure in the rat. Pharmacol Biochem Behav, 66(3), 501-508.

Capela, J., Carmo, H., Remião, F., Bastos, M., Meisel, A., \& Carvalho, F. (2009). Molecular and Cellular Mechanisms of Ecstasy-Induced Neurotoxicity: An Overview. Mol Neurobiol, 39(3), 210-271. 
Carlson, R. G., Falck, R. S., McCaughan, J. A., \& Siegal, H. A. (2004). MDMA/Ecstasy use among young people in Ohio: perceived risk and barriers to intervention. $J$ Psychoactive Drugs, 36(2), 181-189.

Carlsson, A., Bédard, P., Lindqvist, M., \& Magnusson, T. (1972). The influence of nerve-impulse flow on the synthesis and metabolism of hydroxytryptamine. Biochem J, 128(3), 70P-71P.

Carlsson, A., Davis, J. N., Kehr, W., Lindqvist, M., \& Atack, C. V. (1972).

Simultaneous measurement of tyrosine and tryptophan hydroxylase activities in brain in vivo using an inhibitor of the aromatic amino acid decarboxylase.

Naunyn Schmiedebergs Arch Pharmacol, 275(2), 153-168.

Ceci, A., Baschirotto, A., \& Borsini, F. (1994). The inhibitory effect of 8-OH-DPAT on the firing activity of dorsal raphe serotoninergic neurons in rats is attenuated by lesion of the frontal cortex. Neuropharmacology, 33(5), 709-713.

Celada, P., Puig, M. V., Casanovas, J. M., Guillazo, G., \& Artigas, F. (2001). Control of dorsal raphe serotonergic neurons by the medial prefrontal cortex: Involvement of serotonin-1A, GABA(A), and glutamate receptors. J Neurosci, 21(24), 99179929.

Chalmers, D. T., \& Watson, S. J. (1991). Comparative anatomical distribution of 5HT1A receptor mRNA and 5-HT1A binding in rat brain--a combined in situ hybridisation/in vitro receptor autoradiographic study. Brain Research, 561(1), 51-60.

Chamberlain, J., Offord, S. J., Wolfe, B. B., Tyau, L. S., Wang, H. L., \& Frazer, A. (1993). Potency of 5-hydroxytryptaminela agonists to inhibit adenylyl cyclase activity is a function of affinity for the "low-affinity" state of [3H]8-hydroxyN,N-dipropylaminotetralin ([3H]8-OH-DPAT) binding. J Pharmacol Exp Ther, 266(2), 618-625.

Chen, J. C., Turiak, G., Galler, J., \& Volicer, L. (1997). Postnatal changes of brain monoamine levels in prenatally malnourished and control rats. Int J Dev Neurosci, 15(2), 257-263.

Clarke, W. P., Yocca, F. D., \& Maayani, S. (1996). Lack of 5-hydroxytryptamine1Amediated inhibition of adenylyl cyclase in dorsal raphe of male and female rats. J Pharmacol Exp Ther, 277(3), 1259-1266.

Cohen, M. A., Skelton, M. R., Schaefer, T. L., Gudelsky, G. A., Vorhees, C. V., \& Williams, M. T. (2005). Learning and memory after neonatal exposure to 3,4methylenedioxymethamphetamine (ecstasy) in rats: interaction with exposure in adulthood. Synapse, 57(3), 148-159.

Colado, M. I., \& Green, A. R. (1994). A study of the mechanism of MDMA ('ecstasy')induced neurotoxicity of 5-HT neurones using chlormethiazole, dizocilpine and other protective compounds. Br J Pharmacol, 111(1), 131-136.

Colado, M. I., Murray, T. K., \& Green, A. R. (1993). 5-HT loss in rat brain following 3,4-methylenedioxymethamphetamine (MDMA), p-chloroamphetamine and 
fenfluramine administration and effects of chlormethiazole and dizocilpine. $\mathrm{Br} J$ Pharmacol, 108(3), 583-589.

Commins, D. L., Vosmer, G., Virus, R. M., Woolverton, W. L., Schuster, C. R., \& Seiden, L. S. (1987). Biochemical and histological evidence that methylenedioxymethylamphetamine (MDMA) is toxic to neurons in the rat brain. J Pharmacol Exp Ther, 241(1), 338-345.

Conrad, L. C., Leonard, C. M., \& Pfaff, D. W. (1974). Connections of the median and dorsal raphe nuclei in the rat: an autoradiographic and degeneration study. $J$ Comp Neurol, 156(2), 179-205.

Cottler, L. B., Leung, K. S., \& Abdallah, A. B. (2009). Test-re-test reliability of DSMIV adopted criteria for 3,4-methylenedioxymethamphetamine (MDMA) abuse and dependence: a cross-national study. Addiction,.

Cox, R. F., Meller, E., \& Waszczak, B. L. (1993). Electrophysiological evidence for a large receptor reserve for inhibition of dorsal raphe neuronal firing by 5-HT1A agonists. Synapse, 14(4), 297-304.

Cunningham, K. A., Paris, J. M., \& Goeders, N. E. (1992). Chronic cocaine enhances serotonin autoregulation and serotonin uptake binding. Synapse, 11(2), 112-123.

Dafters, R. I. (1995). Hyperthermia following MDMA administration in rats: effects of ambient temperature, water consumption, and chronic dosing. Physiol Behav, $58(5), 877-882$.

Dafters, R. I., \& Lynch, E. (1998). Persistent loss of thermoregulation in the rat induced by 3,4-methylenedioxymethamphetamine (MDMA or "Ecstasy") but not by fenfluramine. Psychopharmacology, 138(2), 207-212.

Dahlström, A., \& Fuxe, K. (1964). Localization of monoamines in the lower brain stem. Experientia, 20(7), 398-399.

Davidson, C., \& Stamford, J. A. (1995). The effect of paroxetine on 5-HT efflux in the rat dorsal raphe nucleus is potentiated by both 5-HT1A and 5-HT1B/D receptor antagonists. Neurosci Lett, 188(1), 41-44.

de la Torre, R., Farré, M., Roset, P. N., Pizarro, N., Abanades, S., Segura, M. et al. (2004). Human pharmacology of MDMA: pharmacokinetics, metabolism, and disposition. Ther Drug Monit, 26(2), 137-144.

De Vivo, M., \& Maayani, S. (1986). Characterization of the 5-hydroxytryptamine1a receptor-mediated inhibition of forskolin-stimulated adenylate cyclase activity in guinea pig and rat hippocampal membranes. J Pharmacol Exp Ther, 238(1), 248-253.

Dong, J., De Montigny, C., \& Blier, P. (1997). Effect of acute and repeated versus sustained administration of the 5-HT1A receptor agonist ipsapirone: electrophysiological studies in the rat hippocampus and dorsal raphe. Naunyn Schmiedebergs Arch Pharmacol, 356(3), 303-311.

Esteban, S., Moranta, D., Sastre-Coll, A., Miralles, A., \& García-Sevilla, J. A. (2002). Withdrawal from chronic ethanol increases the sensitivity of presynaptic 5- 
$\mathrm{HT}(1 \mathrm{~A})$ receptors modulating serotonin and dopamine synthesis in rat brain in vivo. Neurosci Lett, 326(2), 121-124.

Fabre, V., Boutrel, B., Hanoun, N., Lanfumey, L., Fattaccini, C. M., Demeneix, B. et al. (2000). Homeostatic regulation of serotonergic function by the serotonin transporter as revealed by nonviral gene transfer. J Neurosci, 20(13), 5065-5075.

Farfel, G. M., \& Seiden, L. S. (1995). Role of hypothermia in the mechanism of protection against serotonergic toxicity. I. Experiments using 3,4methylenedioxymethamphetamine, dizocilpine, CGS 19755 and NBQX. $J$ Pharmacol Exp Ther, 272(2), 860-867.

Fernstrom, J. D., \& Wurtman, R. J. (1971). Brain serotonin content: physiological dependence on plasma tryptophan levels. Science, 173(992), 149-152.

Fischer, C., Hatzidimitriou, G., Wlos, J., Katz, J., \& Ricaurte, G. (1995).

Reorganization of ascending 5-HT axon projections in animals previously exposed to the recreational drug (+/-)3,4-methylenedioxymethamphetamine (MDMA, "ecstasy"). J Neurosci, 15(8), 5476-5485.

Fone, K. C., Beckett, S. R., Topham, I. A., Swettenham, J., Ball, M., \& Maddocks, L. (2002). Long-term changes in social interaction and reward following repeated MDMA administration to adolescent rats without accompanying serotonergic neurotoxicity. Psychopharmacology, 159(4), 437-444.

Forster, E. A., Cliffe, I. A., Bill, D. J., Dover, G. M., Jones, D., Reilly, Y. et al. (1995). A pharmacological profile of the selective silent 5-HT1A receptor antagonist, WAY-100635. Eur J Pharmacol, 281(1), 81-88.

Fox, H. C., Parrott, A. C., \& Turner, J. J. (2001). Ecstasy use: cognitive deficits related to dosage rather than self-reported problematic use of the drug. $J$ Psychopharmacol (Oxford), 15(4), 273-281.

Freudenmann, R. W., Oxler, F., \& Bernschneider-Reif, S. (2006). The origin of MDMA (ecstasy) revisited: the true story reconstructed from the original documents. Addiction, 101(9), 1241-1245.

Gartside, S. E., McQuade, R., \& Sharp, T. (1996). Effects of repeated administration of 3,4-methylenedioxymethamphetamine on 5-hydroxytryptamine neuronal activity and release in the rat brain in vivo. J Pharmacol Exp Ther, 279(1), 277-283.

Gartside, S. E., McQuade, R., \& Sharp, T. (1997). Acute effects of 3,4methylenedioxymethamphetamine (MDMA) on 5-HT cell firing and release: comparison between dorsal and median raphe 5-HT systems. Neuropharmacology, 36(11-12), 1697-1703.

Gerra, G., Zaimovic, A., Ferri, M., Zambelli, U., Timpano, M., Neri, E. et al. (2000). Long-lasting effects of (+/-)3,4-methylenedioxymethamphetamine (ecstasy) on serotonin system function in humans. Biol Psychiatry, 47(2), 127-136.

Gerra, G., Zaimovic, A., Giucastro, G., Maestri, D., Monica, C., Sartori, R. et al. (1998). Serotonergic function after (+/-)3,4-methylene-dioxymethamphetamine ('Ecstasy') in humans. Int Clin Psychopharmacol, 13(1), 1-9. 
Gold, L. H., Koob, G. F., \& Geyer, M. A. (1988). Stimulant and hallucinogenic behavioral profiles of 3,4-methylenedioxymethamphetamine and N-ethyl-3,4methylenedioxyamphetamine in rats. J Pharmacol Exp Ther, 247(2), 547-555.

Goodwin, G. M., De Souza, R. J., Green, A. R., \& Heal, D. J. (1987). The pharmacology of the behavioural and hypothermic responses of rats to 8hydroxy-2-(di-n-propylamino)tetralin (8-OH-DPAT). Psychopharmacology, 91(4), 506-511.

Gough, B., Ali, S. F., Slikker, W., \& Holson, R. R. (1991). Acute effects of 3,4methylenedioxymethamphetamine (MDMA) on monoamines in rat caudate. Pharmacol Biochem Behav, 39(3), 619-623.

Gouzoulis-Mayfrank, E., Becker, S., Pelz, S., Tuchtenhagen, F., \& Daumann, J. (2002). Neuroendocrine abnormalities in recreational ecstasy (MDMA) users: is it ecstasy or cannabis? Biol Psychiatry, 51(9), 766-769.

Gowing, L., Henry-Hedwards, S., Irvine, R., \& Ali, R. (2001). Ecstasy: MDMA and other ring-substituted amphetamines. World Health Organization, 1(1), 1-96.

Gozlan, H., El Mestikawy, S., Pichat, L., Glowinski, J., \& Hamon, M. (1983). Identification of presynaptic serotonin autoreceptors using a new ligand: $3 \mathrm{H}-$ PAT. Nature, 305(5930), 140-142.

Granoff, M. I., \& Ashby, C. R. (2001). Effect of the repeated administration of (+/-)3,4-methylenedioxymethamphetamine on the behavioral response of rats to the 5-HT1A receptor agonist (+/-)-8-hydroxy-(di-n-propylamino)tetralin. Neuropsychobiology, 43(1), 42-48.

Green, A. R., Cross, A. J., \& Goodwin, G. M. (1995). Review of the pharmacology and clinical pharmacology of 3,4-methylenedioxymethamphetamine (MDMA or "Ecstasy"). Psychopharmacology, 119(3), 247-260.

Green, A. R., Mechan, A. O., Elliott, J. M., O'Shea, E., \& Colado, M. I. (2003). The pharmacology and clinical pharmacology of 3,4methylenedioxymethamphetamine (MDMA, "ecstasy"). Pharmacol Rev, 55(3), 463-508.

Greer, G. R., \& Tolbert, R. (1998). A method of conducting therapeutic sessions with MDMA. J Psychoactive Drugs, 30(4), 371-379.

Gudelsky, G. A., \& Nash, J. F. (1996). Carrier-mediated release of serotonin by 3,4methylenedioxymethamphetamine: implications for serotonin-dopamine interactions. J Neurochem, 66(1), 243-249.

Gurtman, C. G., Morley, K. C., Li, K. M., Hunt, G. E., \& McGregor, I. S. (2002). Increased anxiety in rats after 3,4-methylenedioxymethamphetamine: association with serotonin depletion. Eur J Pharmacol, 446(1-3), 89-96.

Hajós, M., Hajós-Korcsok, E., \& Sharp, T. (1999). Role of the medial prefrontal cortex in 5-HT1A receptor-induced inhibition of 5-HT neuronal activity in the rat. $\mathrm{Br} \mathrm{J}$ Pharmacol, 126(8), 1741-1750. 
Hall, M. D., El Mestikawy, S., Emerit, M. B., Pichat, L., Hamon, M., \& Gozlan, H. (1985). [3H]8-hydroxy-2-(di-n-propylamino)tetralin binding to pre- and postsynaptic 5-hydroxytryptamine sites in various regions of the rat brain. $J$ Neurochem, 44(6), 1685-1696.

Hamon, M., Fattaccini, C. M., Adrien, J., Gallissot, M. C., Martin, P., \& Gozlan, H. (1988). Alterations of central serotonin and dopamine turnover in rats treated with ipsapirone and other 5-hydroxytryptamine1 A agonists with potential anxiolytic properties. $J$ Pharmacol Exp Ther, 246(2), 745-752.

Harlan Labs. (2009). Sprague Dawley (SD) Weight Chart. Retrieved January 10th, 2011, from http://www.harlan.com/download.axd/00aa0d5adcd2497faa267a3cacf8587c.pdf.

Hedlund, P. B., Kelly, L., Mazur, C., Lovenberg, T., Sutcliffe, J. G., \& Bonaventure, P. (2004). 8-OH-DPAT acts on both 5-HT1A and 5-HT7 receptors to induce hypothermia in rodents. Eur J Pharmacol, 487(1-3), 125-132.

Heffner, T. G., Hartman, J. A., \& Seiden, L. S. (1980). A rapid method for the regional dissection of the rat brain. Pharmacol Biochem Behav, 13(3), 453-456.

Helke, C. J., Capuano, S., Tran, N., \& Zhuo, H. (1997). Immunocytochemical studies of the 5-HT(1A) receptor in ventral medullaryneurons that project to the intermediolateral cell column and contain serotonin or tyrosine hydroxylase immunoreactivity. J Comp Neurol, 379(2), 261-270.

Higgins, G. A., Bradbury, A. J., Jones, B. J., \& Oakley, N. R. (1988). Behavioural and biochemical consequences following activation of 5HT1-like and GABA receptors in the dorsal raphé nucleus of the rat. Neuropharmacology, 27(10), 993-1001.

Hillegaart, V. (1991). Effects of local application of 5-HT and 8-OH-DPAT into the dorsal and median raphe nuclei on core temperature in the rat. Psychopharmacology, 103(3), 291-296.

Hillegaart, V., Hjorth, S., \& Ahlenius, S. (1990). Effects of 5-HT and 8-OH-DPAT on forebrain monoamine synthesis after local application into the median and dorsal raphe nuclei of the rat. J Neural Transm Gen Sect, 81(2), 131-145.

Hjorth, S. (1985). Hypothermia in the rat induced by the potent serotoninergic agent 8OH-DPAT. Journal of neural transmission.

Hjorth, S., Carlsson, A., Lindberg, P., \& Sanchez, D. (1982). 8-Hydroxy-2-(di-npropylamino) tetralin, 8-OH-DPAT, a potent and selective simplified ergot congener with central 5-HT-receptor stimulating activity. Journal of Neural ....

Hjorth, S., \& Magnusson, T. (1988). The 5-HT 1A receptor agonist, 8-OH-DPAT, preferentially activates cell body 5-HT autoreceptors in rat brain in vivo. Naunyn Schmiedebergs Arch Pharmacol, 338(5), 463-471.

Ho, Y. J., Pawlak, C. R., Guo, L., \& Schwarting, R. K. (2004). Acute and long-term consequences of single MDMA administration in relation to individual anxiety levels in the rat. Behav Brain Res, 149(2), 135-144. 
(2010). Drug Misuse Declared: Findings from the 2009/10 British Crime Survey England and Wales. http://rds.homeoffice.gov.uk/rds/hosbpubs1.html.

Hoyer, D., Clarke, D. E., Fozard, J. R., Hartig, P. R., Martin, G. R., Mylecharane, E. J. et al. (1994). International Union of Pharmacology classification of receptors for 5-hydroxytryptamine (Serotonin). Pharmacol Rev, 46(2), 157-203.

Hoyer, D., Hannon, J. P., \& Martin, G. R. (2002). Molecular, pharmacological and functional diversity of 5-HT receptors. Pharmacol Biochem Behav, 71(4), 533554.

Imai, H., Steindler, D. A., \& Kitai, S. T. (1986). The organization of divergent axonal projections from the midbrain raphe nuclei in the rat. J Comp Neurol, 243(3), 363-380.

Innis, R. B., \& Aghajanian, G. K. (1987). Pertussis toxin blocks 5-HT1A and GABAB receptor-mediated inhibition of serotonergic neurons. Eur J Pharmacol, 143(2), 195-204.

Innis, R. B., Nestler, E. J., \& Aghajanian, G. K. (1988). Evidence for G protein mediation of serotonin- and GABAB-induced hyperpolarization of rat dorsal raphe neurons. Brain Research, 459(1), 27-36.

Jacobs, B. L., Foote, S. L., \& Bloom, F. E. (1978). Differential projections of neurons within the dorsal raphe nucleus of the rat: a horseradish peroxidase (HRP) study. Brain Research, 147(1), 149-153.

Jensen, K. F., Olin, J., Haykal-Coates, N., O'Callaghan, J., Miller, D. B., \& de Olmos, J. S. (1993). Mapping toxicant-induced nervous system damage with a cupric silver stain: a quantitative analysis of neural degeneration induced by 3,4methylenedioxymethamphetamine. NIDA Res Monogr, 136, 133-49; discussion $150-4$

Johnson, M., Mitros, K., Stone, D. M., Zobrist, R., Hanson, G. R., \& Gibb, J. W. (1992). Effect of flunarizine and nimodipine on the decrease in tryptophan hydroxylase activity induced by methamphetamine and 3,4methylenedioxymethamphetamine. J Pharmacol Exp Ther, 261(2), 586-591.

Johnson, M. P., Hoffman, A. J., \& Nichols, D. E. (1986). Effects of the enantiomers of MDA, MDMA and related analogues on $[3 \mathrm{H}]$ serotonin and $[3 \mathrm{H}]$ dopamine release from superfused rat brain slices. Eur J Pharmacol, 132(2-3), 269-276.

Johnson, R. G., Fiorella, D., Winter, J. C., \& Rabin, R. A. (1997). [3H]8-OH-DPAT labels a 5-HT site coupled to inhibition of phosphoinositide hydrolysis in the dorsal raphe. Eur J Pharmacol, 329(1), 99-106.

Johnston, L., O'Malley, P., Bachman, J., \& Schulenberg, J. (2010). Monitoring the Future: National Results on Adolescent Drug Use. Overview of Key Findings, 2009. http://monitoringthefuture.org/.

Jolas, T., Schreiber, R., Laporte, A. M., Chastanet, M., De Vry, J., Glaser, T. et al. (1995). Are postsynaptic 5-HT1A receptors involved in the anxiolytic effects of 
5-HT1A receptor agonists and in their inhibitory effects on the firing of serotonergic neurons in the rat? J Pharmacol Exp Ther, 272(2), 920-929.

Joseph, M. H., \& Kennett, G. A. (1983). Stress-induced release of 5-HT in the hippocampus and its dependence on increased tryptophan availability: an in vivo electrochemical study. Brain Research, 270(2), 251-257.

Kankaanpää, A., Meririnne, E., Lillsunde, P., \& Seppälä, T. (1998). The acute effects of amphetamine derivatives on extracellular serotonin and dopamine levels in rat nucleus accumbens. Pharmacol Biochem Behav, 59(4), 1003-1009.

Kelaï, S., Renoir, T., Chouchana, L., Saurini, F., Hanoun, N., Hamon, M. et al. (2008). Chronic voluntary ethanol intake hypersensitizes 5-HT1Aautoreceptors in C57BL/6J mice. J Neurochem, 107(6), 1660-1670.

Kia, H. K., Brisorgueil, M. J., Daval, G., Langlois, X., Hamon, M., \& Vergé, D. (1996). Serotonin1A receptors are expressed by a subpopulation of cholinergic neurons in the rat medial septum and diagonal band of Broca--a double immunocytochemical study. Neuroscience, 74(1), 143-154.

Kia, H. K., Brisorgueil, M. J., Hamon, M., Calas, A., \& Vergé, D. (1996). Ultrastructural localization of 5-hydroxytryptamine1A receptors in the rat brain. J Neurosci Res, 46(6), 697-708.

Kivell, B., Day, D., Bosch, P., Schenk, S., \& Miller, J. (2010). MDMA causes a redistribution of serotonin transporter from the cell surface to the intracellular compartment by a mechanism independent of phospho-p38-mitogen activated protein kinase activation. Neuroscience, 168(1), 82-95.

Kreiss, D. S., \& Lucki, I. (1994). Differential regulation of serotonin (5-HT) release in the striatum and hippocampus by 5-HT1A autoreceptors of the dorsal and median raphe nuclei. J Pharmacol Exp Ther, 269(3), 1268-1279.

Kreiss, D. S., \& Lucki, I. (1997). Chronic administration of the 5-HT1A receptor agonist 8-OH-DPAT differentially desensitizes 5-HT1A autoreceptors of the dorsal and median raphe nuclei. Synapse, 25(2), 107-116.

Le Poul, E., Boni, C., Hanoun, N., Laporte, A. M., Laaris, N., Chauveau, J. et al. (2000). Differential adaptation of brain 5-HT1A and 5-HT1B receptors and 5-HT transporter in rats treated chronically with fluoxetine. Neuropharmacology, $39(1), 110-122$.

Leonardi, E. T., \& Azmitia, E. C. (1994). MDMA (ecstasy) inhibition of MAO type A and type B: comparisons with fenfluramine and fluoxetine (Prozac). Neuropsychopharmacology, 10(4), 231-238.

Maeda, J., Suhara, T., Ogawa, M., Okauchi, T., Kawabe, K., Zhang, M. R. et al. (2001). In vivo binding properties of [carbonyl-11C]WAY-100635: effect of endogenous serotonin. Synapse, 40(2), 122-129.

Malberg, J. E., \& Seiden, L. S. (1998). Small changes in ambient temperature cause large changes in 3,4-methylenedioxymethamphetamine (MDMA)-induced 
serotonin neurotoxicity and core body temperature in the rat. $J$ Neurosci, $18(13)$, 5086-5094.

Malison, R. T., Price, L. H., Berman, R., van Dyck, C. H., Pelton, G. H., Carpenter, L. et al. (1998). Reduced brain serotonin transporter availability in major depression as measured by [123I]-2 beta-carbomethoxy-3 beta-(4iodophenyl)tropane and single photon emission computed tomography. Biol Psychiatry, 44(11), 1090-1098.

Marazziti, D., Palego, L., Giromella, A., Mazzoni, M. R., Borsini, F., Mayer, N. et al. (2002). Region-dependent effects of flibanserin and buspirone on adenylyl cyclase activity in the human brain. Int J Neuropsychopharmacol, 5(2), 131-140.

Marston, H. M., Reid, M. E., Lawrence, J. A., Olverman, H. J., \& Butcher, S. P. (1999). Behavioural analysis of the acute and chronic effects of MDMA treatment in the rat. Psychopharmacology, 144(1), 67-76.

Matuszewich, L., Filon, M. E., Finn, D. A., \& Yamamoto, B. K. (2002). Altered forebrain neurotransmitter responses to immobilization stress following 3,4methylenedioxymethamphetamine. Neuroscience, 110(1), 41-48.

McCann, U. D., Mertl, M., Eligulashvili, V., \& Ricaurte, G. A. (1999). Cognitive performance in (+/-) 3,4-methylenedioxymethamphetamine (MDMA, "ecstasy") users: a controlled study. Psychopharmacology, 143(4), 417-425.

McCann, U. D., Ridenour, A., Shaham, Y., \& Ricaurte, G. A. (1994). Serotonin neurotoxicity after (+/-)3,4-methylenedioxymethamphetamine (MDMA; "Ecstasy"): a controlled study in humans. Neuropsychopharmacology, 10(2), 129-138.

McCann, U. D., Szabo, Z., Scheffel, U., Dannals, R. F., \& Ricaurte, G. A. (1998). Positron emission tomographic evidence of toxic effect of MDMA ("Ecstasy") on brain serotonin neurons in human beings. Lancet, 352(9138), 1433-1437.

McCann, U. D., Szabo, Z., Vranesic, M., Palermo, M., Mathews, W. B., Ravert, H. T. et al. (2008). Positron emission tomographic studies of brain dopamine and serotonin transporters in abstinent (+/-)3,4-methylenedioxymethamphetamine ("ecstasy") users: relationship to cognitive performance. Psychopharmacology, 200(3), 439-450.

McCardle, K., Luebbers, S., Carter, J. D., Croft, R. J., \& Stough, C. (2004). Chronic MDMA (ecstasy) use, cognition and mood. Psychopharmacology, 173(3-4), 434-439.

McDowell, D., \& Kleber, H. (1994). MDMA: its history and pharmacology. Psychiatric Annals, 24(3), 127-130.

McEntee, W. J., \& Crook, T. H. (1991). Serotonin, memory, and the aging brain. Psychopharmacology, 103(2), 143-149.

Mcgregor, I., Gurtman, C., Morley, K., Clemens, K., Blokland, A., Li, K. et al. (2003a). Increased anxiety and "depressive" symptoms months after MDMA ("ecstasy") 
in rats: drug-induced hyperthermia does not predict long-term outcomes. Psychopharmacology, 168(4), 465-474.

McGregor, I. S., Clemens, K. J., Van der Plasse, G., Li, K. M., Hunt, G. E., Chen, F. et al. (2003b). Increased anxiety 3 months after brief exposure to MDMA ("Ecstasy") in rats: association with altered 5-HT transporter and receptor density. Neuropsychopharmacology, 28(8), 1472-1484.

McNamara, M. G., Kelly, J. P., \& Leonard, B. E. (1995). Some behavioural and neurochemical aspects of subacute (+/-)3,4-methylenedioxymethamphetamine administration in rats. Pharmacol Biochem Behav, 52(3), 479-484.

Measham, F., \& Moore, K. (2009). Repertoires of distinction: Exploring patterns of weekend polydrug use within local leisure scenes across the English night time economy. Criminology and Criminal Justice, 9(4), 437.

Mechan, A. O., Moran, P. M., Elliott, M., Young, A. J., Joseph, M. H., \& Green, R. (2002). A study of the effect of a single neurotoxic dose of 3,4methylenedioxymethamphetamine (MDMA; "ecstasy") on the subsequent longterm behaviour of rats in the plus maze and open field. Psychopharmacology, 159(2), 167-175.

Mechan, A. O., O'Shea, E., Elliott, J. M., Colado, M. I., \& Green, A. R. (2001). A neurotoxic dose of 3,4-methylenedioxymethamphetamine (MDMA; ecstasy) to rats results in a long-term defect in thermoregulation. Psychopharmacology, $155(4), 413-418$.

Meller, E., Goldstein, M., \& Bohmaker, K. (1990). Receptor reserve for 5hydroxytryptamine1A-mediated inhibition of serotonin synthesis: possible relationship to anxiolytic properties of 5-hydroxytryptamine1 A agonists. Mol Pharmacol, 37(2), 231-237.

Miller, D. B., \& O'Callaghan, J. P. (1994). Environment-, drug- and stress-induced alterations in body temperature affect the neurotoxicity of substituted amphetamines in the C57BL/6J mouse. J Pharmacol Exp Ther, 270(2), 752-760.

Miller, J. J., Richardson, T. L., Fibiger, H. C., \& McLennan, H. (1975). Anatomical and electrophysiological identification of a projection from the mesencephalic raphe to the caudate-putamen in the rat. Brain Research, 97(1), 133-136.

Mithoefer, M. C., Wagner, M. T., Mithoefer, A. T., Jerome, I., \& Doblin, R. (2010). The safety and efficacy of $\{+/-\} 3,4-$-methylenedioxymethamphetamine-assisted psychotherapy in subjects with chronic, treatment-resistant posttraumatic stress disorder: the first randomized controlled pilot study. J Psychopharmacol (Oxford),

Moore, N. A., Rees, G., Sanger, G., \& Perrett, L. (1993). 5-HT1A-mediated lower lip retraction: effects of 5-HT1A agonists and antagonists. Pharmacol Biochem Behav, 46(1), 141-143.

Morgan, M. J. (2000). Ecstasy (MDMA): a review of its possible persistent psychological effects. Psychopharmacology, 152(3), 230-248. 
Morley, K. C., Gallate, J. E., Hunt, G. E., Mallet, P. E., \& McGregor, I. S. (2001). Increased anxiety and impaired memory in rats 3 months after administration of 3,4-methylenedioxymethamphetamine ("ecstasy"). Eur J Pharmacol, 433(1), 91-99.

Müller, C. P., Carey, R. J., Huston, J. P., \& De Souza Silva, M. A. (2007). Serotonin and psychostimulant addiction: focus on 5-HT1A-receptors. Prog Neurobiol, 81(3), 133-178.

Nair, S. G., \& Gudelsky, G. A. (2006). Effect of a serotonin depleting regimen of 3,4methylenedioxymethamphetamine (MDMA) on the subsequent stimulation of acetylcholine release in the rat prefrontal cortex. Brain Res Bull, 69(4), 382-387.

Nash, J. F., Meltzer, H. Y., \& Gudelsky, G. A. (1988). Elevation of serum prolactin and corticosterone concentrations in the rat after the administration of 3,4methylenedioxymethamphetamine. J Pharmacol Exp Ther, 245(3), 873-879.

Nichols, D. E., Lloyd, D. H., Hoffman, A. J., Nichols, M. B., \& Yim, G. K. (1982). Effects of certain hallucinogenic amphetamine analogues on the release of $[3 \mathrm{H}]$ serotonin from rat brain synaptosomes. J Med Chem, 25(5), 530-535.

Nichols, D. E., \& Oberlender, R. (1990). Structure-activity relationships of MDMA and related compounds: a new class of psychoactive drugs? Ann N Y Acad Sci, 600, 613-23; discussion 623-5.

Nutt, D. (2008). MDMA ('ecstasy'): a review of its harms and classification under the Misuse of Drugs Act 1971., 1-49.

O'Cain, P. A., Hletko, S. B., Ogden, B. A., \& Varner, K. J. (2000). Cardiovascular and sympathetic responses and reflex changes elicited by MDMA. Physiol Behav, 70(1-2), 141-148.

O'Callaghan, J. P., Jensen, K. F., \& Miller, D. B. (1995). Quantitative aspects of drug and toxicant-induced astrogliosis. Neurochem Int, 26(2), 115-124.

O'Callaghan, J. P., \& Sriram, K. (2005). Glial fibrillary acidic protein and related glial proteins as biomarkers of neurotoxicity. Expert Opin Drug Saf, 4(3), 433-442.

O'Connell, M. T., Sarna, G. S., \& Curzon, G. (1992). Evidence for postsynaptic mediation of the hypothermic effect of 5-HT1A receptor activation. $\mathrm{Br} J$ Pharmacol, 106(3), 603-609.

O'Hearn, E., Battaglia, G., De Souza, E. B., Kuhar, M. J., \& Molliver, M. E. (1988). Methylenedioxyamphetamine (MDA) and methylenedioxymethamphetamine (MDMA) cause selective ablation of serotonergic axon terminals in forebrain: immunocytochemical evidence for neurotoxicity. J Neurosci, 8(8), 2788-2803.

O'Shea, E., Granados, R., Esteban, B., Colado, M. I., \& Green, A. R. (1998). The relationship between the degree of neurodegeneration of rat brain 5-HT nerve terminals and the dose and frequency of administration of MDMA ('ecstasy'). Neuropharmacology, 37(7), 919-926. 
O'Shea, E., Orio, L., Escobedo, I., Sanchez, V., Camarero, J., Green, A. R. et al. (2006). MDMA-induced neurotoxicity: long-term effects on 5-HT biosynthesis and the influence of ambient temperature. Br J Pharmacol, 148(6), 778-785.

Palego, L., Giromella, A., Marazziti, D., Borsini, F., Naccarato, A. G., Giannaccini, G. et al. (1999). Effects of postmortem delay on serotonin and (+)8-OH-DPATmediated inhibition of adenylyl cyclase activity in rat and human brain tissues. Brain Research, 816(1), 165-174.

Parrott, A. C. (2001). Human psychopharmacology of Ecstasy (MDMA): a review of 15 years of empirical research. Hum Psychopharmacol, 16(8), 557-577.

Parrott, A. C. (2004). Is ecstasy MDMA? A review of the proportion of ecstasy tablets containing MDMA, their dosage levels, and the changing perceptions of purity. Psychopharmacology, 173(3-4), 234-241.

Parrott, A. C., Buchanan, T., Scholey, A. B., Heffernan, T., Ling, J., \& Rodgers, J. (2002). Ecstasy/MDMA attributed problems reported by novice, moderate and heavy recreational users. Hum Psychopharmacol, 17(6), 309-312.

Patel, P. D., Pontrello, C., \& Burke, S. (2004). Robust and tissue-specific expression of TPH2 versus TPH1 in rat raphe and pineal gland. Biol Psychiatry, 55(4), 428433.

Peroutka, S. J., Newman, H., \& Harris, H. (1988). Subjective effects of 3,4methylenedioxymethamphetamine in recreational users. Neuropsychopharmacology, 1(4), 273-277.

Piper, B., \& Meyer, J. (2004). Memory deficit and reduced anxiety in young adult rats given repeated intermittent MDMA treatment during the periadolescent period. Pharmacol Biochem Behav, 79(4), 723-731.

Poland, R. E. (1990). Diminished corticotropin and enhanced prolactin responses to 8hydroxy-2(di-n-propylamino)tetralin in methylenedioxymethamphetamine pretreated rats. Neuropharmacology, 29(11), 1099-1101.

Poland, R. E., Lutchmansingh, P., McCracken, J. T., Zhao, J. P., Brammer, G. L., Grob, C. S. et al. (1997). Abnormal ACTH and prolactin responses to fenfluramine in rats exposed to single and multiple doses of MDMA. Psychopharmacology, 131(4), 411-419.

Polter, A. M., \& Li, X. (2010). 5-HT1A receptor-regulated signal transduction pathways in brain. Cellular Signalling,.

Pompeiano, M., Palacios, J. M., \& Mengod, G. (1992). Distribution and cellular localization of mRNA coding for 5-HT1A receptor in the rat brain: correlation with receptor binding. J Neurosci, 12(2), 440-453.

Price, L. H., Ricaurte, G. A., Krystal, J. H., \& Heninger, G. R. (1989). Neuroendocrine and mood responses to intravenous L-tryptophan in 3,4methylenedioxymethamphetamine (MDMA) users. Preliminary observations. Arch Gen Psychiatry, 46(1), 20-22. 
Pubill, D., Canudas, A. M., Pallàs, M., Camins, A., Camarasa, J., \& Escubedo, E. (2003). Different glial response to methamphetamine- and methylenedioxymethamphetamine-induced neurotoxicity. Naunyn Schmiedebergs Arch Pharmacol, 367(5), 490-499.

Puerta, E., Hervias, I., \& Aguirre, N. (2009). On the mechanisms underlying 3,4methylenedioxymethamphetamine toxicity: the dilemma of the chicken and the egg. Neuropsychobiology, 60(3-4), 119-129.

Rabiner, E. A., Bhagwagar, Z., Gunn, R. N., Cowen, P. J., \& Grasby, P. M. (2004). Preferential 5-HT1A autoreceptor occupancy by pindolol is attenuated in depressed patients: effect of treatment or an endophenotype of depression? Neuropsychopharmacology, 29(9), 1688-1698.

Reneman, L., Booij, J., Schmand, B., van den Brink, W., \& Gunning, B. (2000). Memory disturbances in "Ecstasy" users are correlated with an altered brain serotonin neurotransmission. Psychopharmacology, 148(3), 322-324.

Reneman, L., Endert, E., de Bruin, K., Lavalaye, J., Feenstra, M. G., de Wolff, F. A. et al. (2002). The acute and chronic effects of MDMA ("ecstasy") on cortical 5HT2A receptors in rat and human brain. Neuropsychopharmacology, 26(3), 387396.

Renoir, T., Païzanis, E., Yacoubi, M. E., Saurini, F., Hanoun, N., Melfort, M. et al. (2008). Differential long-term effects of MDMA on the serotoninergic system and hippocampal cell proliferation in 5-HTT knock-out vs. wild-type mice. Int $J$ Neuropsychopharmacol, 11(8), 1149-1162.

Riad, M., Garcia, S., Watkins, K. C., Jodoin, N., Doucet, E., Langlois, X. et al. (2000). Somatodendritic localization of 5-HT1A and preterminal axonal localization of 5-HT1B serotonin receptors in adult rat brain. J Comp Neurol, 417(2), 181-194.

Riad, M., Watkins, K. C., Doucet, E., Hamon, M., \& Descarries, L. (2001). Agonistinduced internalization of serotonin-1a receptors in the dorsal raphe nucleus (autoreceptors) but not hippocampus (heteroreceptors). J Neurosci, 21(21), 8378-8386.

Robinson, T. E., Castañeda, E., \& Whishaw, I. Q. (1993). Effects of cortical serotonin depletion induced by 3,4-methylenedioxymethamphetamine (MDMA) on behavior, before and after additional cholinergic blockade. Neuropsychopharmacology, 8(1), 77-85.

Ropert, N. (1988). Inhibitory action of serotonin in CA1 hippocampal neurons in vitro. Neuroscience, 26(1), 69-81.

Rothman, R. B., \& Baumann, M. H. (2002). Therapeutic and adverse actions of serotonin transporter substrates. Pharmacol Ther, 95(1), 73-88.

Rusyniak, D. E., Zaretskaia, M. V., Zaretsky, D. V., \& DiMicco, J. A. (2007). 3,4Methylenedioxymethamphetamine- and 8-hydroxy-2-di-n-propylamino-tetralininduced hypothermia: role and location of 5-hydroxytryptamine 1A receptors. $J$ Pharmacol Exp Ther, 323(2), 477-487. 
Sabol, K. E., \& Seiden, L. S. (1998). Reserpine attenuates D-amphetamine and MDMAinduced transmitter release in vivo: a consideration of dose, core temperature and dopamine synthesis. Brain Res, 806(1), 69-78.

Samama, P., Cotecchia, S., Costa, T., \& Lefkowitz, R. J. (1993). A mutation-induced activated state of the beta 2-adrenergic receptor. Extending the ternary complex model. J Biol Chem, 268(7), 4625-4636.

Sanchez, V., O'Shea, E., Saadat, K. S., Elliott, J. M., Colado, M. I., \& Green, A. R. (2004). Effect of repeated ('binge') dosing of MDMA to rats housed at normal and high temperature on neurotoxic damage to cerebral 5-HT and dopamine neurones. J Psychopharmacol (Oxford), 18(3), 412-416.

Scanzello, C. R., Hatzidimitriou, G., Martello, A. L., Katz, J. L., \& Ricaurte, G. A. (1993). Serotonergic recovery after (+/-)3,4-(methylenedioxy) methamphetamine injury: observations in rats. J Pharmacol Exp Ther, 264(3), 1484-1491.

Schenk, S. (2009). MDMA self-administration in laboratory animals: a summary of the literature and proposal for future research. Neuropsychobiology, 60(3-4), 130136.

Schenk, S., Gittings, D., Johnstone, M., \& Daniela, E. (2003). Development, maintenance and temporal pattern of self-administration maintained by ecstasy (MDMA) in rats. Psychopharmacology, 169(1), 21-27.

Schenk, S., Hely, L., Lake, B., Daniela, E., Gittings, D., \& Mash, D. C. (2007). MDMA self-administration in rats: acquisition, progressive ratio responding and serotonin transporter binding. Eur J Neurosci, 26(11), 3229-3236.

Schifano, F. (2004). A bitter pill. Overview of ecstasy (MDMA, MDA) related fatalities. Psychopharmacology, 173(3-4), 242-248.

Schmidt, C. J. (1987). Neurotoxicity of the psychedelic amphetamine, methylenedioxymethamphetamine. J Pharmacol Exp Ther, 240(1), 1-7.

Schmidt, C. J., Black, C. K., Abbate, G. M., \& Taylor, V. L. (1990).

Methylenedioxymethamphetamine-induced hyperthermia and neurotoxicity are independently mediated by 5-HT2 receptors. Brain Research, 529(1-2), 85-90.

Scholey, A. B., Parrott, A. C., Buchanan, T., Heffernan, T. M., Ling, J., \& Rodgers, J. (2004). Increased intensity of Ecstasy and polydrug usage in the more experienced recreational Ecstasy/MDMA users: a WWW study. Addict Behav, 29(4), 743-752.

Schuldiner, S., Steiner-Mordoch, S., Yelin, R., Wall, S. C., \& Rudnick, G. (1993). Amphetamine derivatives interact with both plasma membrane and secretory vesicle biogenic amine transporters. Mol Pharmacol, 44(6), 1227-1231.

Segal, M. (1975). Physiological and pharmacological evidence for a serotonergic projection to the hippocampus. Brain Research, 94(1), 115-131.

Seiden, L. S., Woolverton, W. L., Lorens, S. A., Williams, J. E., Corwin, R. L., Hata, N. et al. (1993). Behavioral consequences of partial monoamine depletion in the 
CNS after methamphetamine-like drugs: the conflict between pharmacology and toxicology. NIDA Res Monogr, 136, 34-46; discussion 46-52.

Series, H. G., Cowen, P. J., \& Sharp, T. (1994). ... Chloroamphetamine (PCA), 3, 4methylenedioxymethamphetamine (MDMA) andd-fenfluramine pretreatment attenuatesd-fenfluramine-evoked release of 5-HT in vivo. Psychopharmacology.

Shankaran, M., \& Gudelsky, G. A. (1999). A neurotoxic regimen of MDMA suppresses behavioral, thermal and neurochemical responses to subsequent MDMA administration. Psychopharmacology, 147(1), 66-72.

Shulgin, A. T., \& Nichols, D. E. (1978). Characterization of three new psychotomimetics. In R. C. Stillman \& R. E. Willette (Eds.), The psychopharmacology of the hallucinogens. (pp. 74-83). New York: Pergamon Press.

Singleton, N., Murray, R., \& Tinsley, L. (2006). Measuring different aspects of problem drug use: methodological developments.

http://rds.homeoffice.gov.uk/rds/pdfs06/rdsolr1606.pdf.

Sotelo, C., Cholley, B., El Mestikawy, S., Gozlan, H., \& Hamon, M. (1990). Direct Immunohistochemical Evidence of the Existence of 5-HT1A Autoreceptors on Serotoninergic Neurons in the Midbrain Raphe Nuclei. Eur J Neurosci, 2(12), 1144-1154.

Spanos, L. J., \& Yamamoto, B. K. (1989). Acute and subchronic effects of methylenedioxymethamphetamine [(+/-)MDMA] on locomotion and serotonin syndrome behavior in the rat. Pharmacol Biochem Behav, 32(4), 835-840.

Spear, L. P. (2000). The adolescent brain and age-related behavioral manifestations. Neurosci Biobehav Rev, 24(4), 417-463.

Sprague, J. E., Preston, A. S., Leifheit, M., \& Woodside, B. (2003). Hippocampal serotonergic damage induced by MDMA (ecstasy): effects on spatial learning. Physiol Behav, 79(2), 281-287.

Sprouse, J. S., \& Aghajanian, G. K. (1987). Electrophysiological responses of serotoninergic dorsal raphe neurons to 5-HT1A and 5-HT1B agonists. Synapse, $1(1), 3-9$.

Sprouse, J. S., \& Aghajanian, G. K. (1988). Responses of hippocampal pyramidal cells to putative serotonin 5-HT1A and 5-HT1B agonists: a comparative study with dorsal raphe neurons. Neuropharmacology, 27(7), 707-715.

Stone, D. M., Johnson, M., Hanson, G. R., \& Gibb, J. W. (1989). Acute inactivation of tryptophan hydroxylase by amphetamine analogs involves the oxidation of sulfhydryl sites. Eur J Pharmacol, 172(1), 93-97.

Stone, D. M., Merchant, K. M., Hanson, G. R., \& Gibb, J. W. (1987). Immediate and long-term effects of 3,4-methylenedioxymethamphetamine on serotonin pathways in brain of rat. Neuropharmacology, 26(12), 1677-1683. 
Sumnall, H. R., O'Shea, E., Marsden, C. A., \& Cole, J. C. (2004). The effects of MDMA pretreatment on the behavioural effects of other drugs of abuse in the rat elevated plus-maze test. Pharmacol Biochem Behav, 77(4), 805-814.

Topp, L., Hando, J., Dillon, P., Roche, A., \& Solowij, N. (1999). Ecstasy use in Australia: patterns of use and associated harm. Drug and alcohol dependence, 55(1-2), 105-115.

Tozer, T., Neff, N., \& Brodie, B. (1966). Application of steady state kinetics to the synthesis rate and turnover time of serotonin in the brain of normal and reserpine-treated rats. Journal of Pharmacology and Experimental Therapeutics, $153(2), 177$.

UNODC. (2010). World Drug Report. United Nations Office on Drugs and Crime http://www.unodc.org/unodc/data-and-analysis/WDR.html.

Vergé, D., Daval, G., Marcinkiewicz, M., Patey, A., el Mestikawy, S., Gozlan, H. et al. (1986). Quantitative autoradiography of multiple 5-HT1 receptor subtypes in the brain of control or 5,7-dihydroxytryptamine-treated rats. J Neurosci, 6(12), 3474-3482.

Verge, D., Daval, G., Patey, A., Gozlan, H., El Mestikawy, S., \& Hamon, M. (1985). Presynaptic 5-HT autoreceptors on serotonergic cell bodies and/or dendrites but not terminals are of the 5-HT1A subtype. Eur J Pharmacol, 113(3), 463-464.

Verheyden, S. L., Henry, J. A., \& Curran, H. V. (2003). Acute, sub-acute and long-term subjective consequences of 'ecstasy' (MDMA) consumption in 430 regular users. Hum Psychopharmacol, 18(7), 507-517.

Vorhees, C. V., Reed, T. M., Skelton, M. R., \& Williams, M. T. (2004). Exposure to 3,4-methylenedioxymethamphetamine (MDMA) on postnatal days 11-20 induces reference but not working memory deficits in the Morris water maze in rats: implications of prior learning. Int J Dev Neurosci, 22(5-6), 247-259.

Walther, D. J., \& Bader, M. (2003). A unique central tryptophan hydroxylase isoform. Biochem Pharmacol, 66(9), 1673-1680.

Wang, X., Baumann, M. H., Dersch, C. M., \& Rothman, R. B. (2007). Restoration of 3,4-methylenedioxymethamphetamine-induced 5-HT depletion by the administration of L-5-hydroxytryptophan. Neuroscience, 148(1), 212-220.

Wang, X., Baumann, M. H., Xu, H., Morales, M., \& Rothman, R. B. (2005). (+/-)-3,4Methylenedioxymethamphetamine administration to rats does not decrease levels of the serotonin transporter protein or alter its distribution between endosomes and the plasma membrane. J Pharmacol Exp Ther, 314(3), 10021012 .

Wang, X., Baumann, M. H., Xu, H., \& Rothman, R. B. (2004). 3,4methylenedioxymethamphetamine (MDMA) administration to rats decreases brain tissue serotonin but not serotonin transporter protein and glial fibrillary acidic protein. Synapse, 53(4), 240-248. 
White, S. R., Obradovic, T., Imel, K. M., \& Wheaton, M. J. (1996). The effects of methylenedioxymethamphetamine (MDMA, "Ecstasy") on monoaminergic neurotransmission in the central nervous system. Prog Neurobiol, 49(5), 455479.

Wilkins, C., Bhatta, K., Pledger, M., \& Casswell, S. (2003). Ecstasy use in New Zealand: findings from the 1998 and 2001 National Drug Surveys. $N Z$ Med J, $116(1171), \mathrm{U} 383$.

Wilkins, C., Griffiths, R., \& Sweetsur, P. (2009). 2008 IDMS Report. http://www.shore.ac.nz/projects/2008_IDMS_executive_summary.pdf.

Wilkins, C., Sweetsur, P., \& Casswell, S. (2006). Recent population trends in amphetamine use in New Zealand: comparisons of findings from national household drug surveying in 1998, 2001, and 2003. Journal of the New Zealand Medical Association, 119, 1244.

Williams, M. T., Morford, L. L., Wood, S. L., Rock, S. L., McCrea, A. E., Fukumura, M. et al. (2003). Developmental 3,4-methylenedioxymethamphetamine (MDMA) impairs sequential and spatial but not cued learning independent of growth, litter effects or injection stress. Brain Research, 968(1), 89-101.

Xie, T., Tong, L., McLane, M. W., Hatzidimitriou, G., Yuan, J., McCann, U. et al. (2006). Loss of serotonin transporter protein after MDMA and other ringsubstituted amphetamines. Neuropsychopharmacology, 31(12), 2639-2651.

Yamamoto, B. K., Nash, J. F., \& Gudelsky, G. A. (1995). Modulation of methylenedioxymethamphetamine-induced striatal dopamine release by the interaction between serotonin and gamma-aminobutyric acid in the substantia nigra. J Pharmacol Exp Ther, 273(3), 1063-1070.

Zill, P., Büttner, A., Eisenmenger, W., Möller, H. J., Ackenheil, M., \& Bondy, B. (2007). Analysis of tryptophan hydroxylase I and II mRNA expression in the human brain: a post-mortem study. J Psychiatr Res, 41(1-2), 168-173. 